\title{
Review \\ The Opto-Electronic Functional Devices Based on Three-Dimensional Lead Halide Perovskites
}

\author{
Henan Liu ${ }^{1,2}$, Hao Zhang ${ }^{1}$, Xunling $\mathrm{Xu}{ }^{1}$ and Lin Zhang ${ }^{1, *}$ \\ 1 Key Laboratory of Opto-Electronic Information Technology of Ministry of Education, \\ School of Precision Instrument and Opto-Electronics Engineering, Tianjin University, Tianjin 300072, China; \\ henanliu@tiangong.edu.cn (H.L.); hao_zhang@tju.edu.cn (H.Z.); xuxunling@tju.edu.cn (X.X.) \\ 2 School of Physical Science and Technology, Tiangong University, Tianjin 300387, China \\ * Correspondence: lin_zhang@tju.edu.cn
}

check for updates

Citation: Liu, H.; Zhang, H.; Xu, X.; Zhang, L. The Opto-Electronic Functional Devices Based on Three-Dimensional Lead Halide Perovskites. Appl. Sci. 2021, 11, 1453. https://doi.org/10.3390/app11041453

Received: 7 December 2020 Accepted: 28 December 2020 Published: 5 February 2021

Publisher's Note: MDPI stays neutral with regard to jurisdictional clai$\mathrm{ms}$ in published maps and institutional affiliations.

Copyright: (C) 2021 by the authors. Licensee MDPI, Basel, Switzerland. This article is an open access article distributed under the terms and conditions of the Creative Commons Attribution (CC BY) license (https:// creativecommons.org/licenses/by/ $4.0 /)$.

\begin{abstract}
These days, opto-electronic functional devices based on three-dimensional lead halide perovskites (LHPs) are emerging. LHPs could be spin-coated to other materials, making it very convenient to combine LHPs with different categories of materials including metals, semiconductors, and polymers and achieve high-level performances. In this review, we will discuss the development in the LHP-based functional devices in recent years. After a brief presentation of the LHP's properties, we will focus on the functional devices including lasers, photodetectors, and modulators. Then the fabrication of the LHP-based devices will be presented, which is followed by the summary and outlook.
\end{abstract}

Keywords: metal-halide perovskite; functional devices; device configuration; lithography

\section{Introduction}

The three-dimensional (3D) lead halide perovskites (LHPs) are enjoying rapid developments as novel opto-electronic materials since their emergence in photovoltaic applications in 2009. LHPs belong to the larger material family of metal halide perovskites (MHPs), which exhibit very similar structure with $\mathrm{CaTiO}_{3}$ and could be generally represented by the formula of $\mathrm{ABX}_{3}$. $\mathrm{X}$ represents the halide anion forming octahedrons, which could be $\mathrm{Cl}^{-}, \mathrm{Br}^{-}$, and $\mathrm{I}^{-}$[1]. B represents cation locating in the center of octahedron, which could be $\mathrm{Pb}^{2+}, \mathrm{Sn}^{2+}$, and $\mathrm{Ge}^{2+}$ in the more generalized cases of MHPs [2-4] but restricted to be $\mathrm{Pb}^{2+}$ for LHPs. A represents the cation locating in the vacancy of neighboring octahedron cages, which could be either organic or inorganics: the inorganic examples include $\mathrm{Cs}^{+}[5]$, while the organic examples include the methylammonium [6,7], formamidinium [8,9], and recently discovered methylhydrazinium $[10,11]$. It is expected that inorganic counterparts generally maintain better chemical stability than their organic counterparts [12]. When specified to the 3D LHPs, the materials have advantageous properties from more than one aspect, and people are eager to utilize them as working materials in various opto-electronic devices. In addition to solar cells [1,13], the materials are also utilized in lasers [7,14], light emitting diodes (LEDs) [15-17], photodetectors [18-20], modulators [21-23], and so on. Moreover, the materials, especially those with bromides, are found to exhibit outstanding nonlinear properties [10,24-27], thus demonstrating promising potential in applications such as imaging, optical limiting, and frequency conversion. Currently, people are incorporating the LHPs into waveguides and micro optical cavities, so as to further miniaturize the LHP-based devices. These efforts are leading to the emergence of integrated photonic/optical systems centering LHPs, which will play a significant role in next-generation opto-electronic applications, resulting in devices not only frequently used in the field of scientific research but also that of consumer electronics. In Figure 1, the crystalline structure of LHP is presented in the center, which is surrounded by examples of potential applications for the LHP-based devices. 


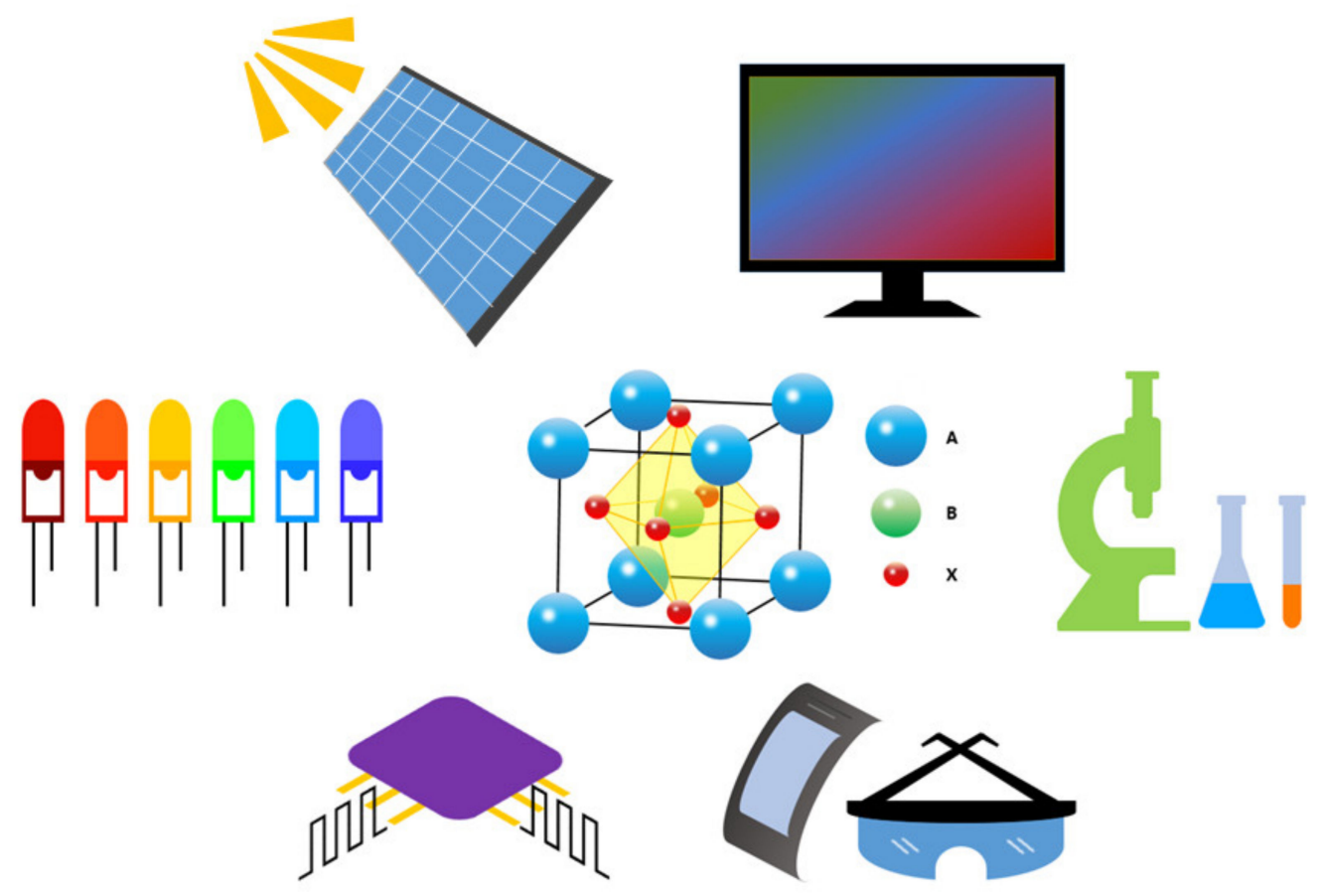

Figure 1. Lead halide perovskites (LHPs) and their potential applications in various fields, including photovoltaic, illumination, communication, wearable devices, chemical test, and high-resolution display.

In addition to the prosperity of LHP material, novel opto-electronic materials including the atomically thin two-dimensional materials (2D) and one-dimensional (1D) materials are also rapidly growing. These materials, each with their unique properties in certain aspects, are also at the center of attention in the research community. LHPs, along with other materials, are all building blocks to construct devices. To some extent, people are free to choose from this "material bank" to fabricate devices and achieve better performances. In most cases, it is quite rigorous that a single species of material could cover all the application demands and introduce no impediments at the same time. On the other hand, it is more practical to combine different materials into the device and make them collaborate such that the advantages from the participants could be utilized, and the shortages could be made up to some extent. The LHP could be fabricated by solution-based methods and conveniently incorporated with semiconductors, metals, and polymers, making it very practical to construct LHP hybrid devices. By now, people have developed LHP hybrid devices covering lasers, photodetectors, modulators, and so on. The materials in collaboration with LHP include novel materials (for instance, graphene and 2D $\mathrm{MoS}_{2}$, etc.) and traditional materials (for instance, silicon). In these devices, the advantageous properties of participating materials are exploited, and the device performances have been improved substantially as compared to the devices made from single species of material. It is beneficial to retrospect these valuable works, which could light up more inspiration and enlightenment for future development in LHP hybrid devices. In this review, we will firstly present the LHPs' properties briefly, related closely to their working performance and stability. Then we will present the LHP hybrid functional devices including lasers, photodetectors, and modulators. Then, the fabrication of the LHP based devices will be presented, which is followed by a summary and outlook as the ending part.

\section{The Properties of the LHP Materials}

Due to the uniqueness of LHP, when a certain device is to be proposed, both the material's opto-electronic property and its stability need to be considered carefully. In this part, the optical and electrical properties of LHP will be summarized, followed by the material's property on stability. 


\subsection{Optical and Electrical Properties of LHP}

The LHPs are considered as outstanding candidates for next-generation opto-electronic applications, mostly due to the fact that the materials demonstrate outstanding optical and electrical properties in various aspects, as shown in Figure 2. The LHPs are direct band-gap semiconductors, and the band-gap could be conveniently tuned by chemical composition (for instance, changing the halogen elements) and thus enabled to cover a wavelength range from visible to near-infrared [28,29]. The LHPs have large absorption coefficients. Taking $\mathrm{CH}_{3} \mathrm{NH}_{3} \mathrm{PbI}_{3}\left(\mathrm{MAPbI}_{3}\right)$ as an example, its absorption coefficient is found to be in the level of $\sim 10^{5} \mathrm{~cm}^{-1}$ in the visible range, being much larger than GaAs [30]. A large absorption coefficient, as well as a widely tunable bandgap, will contribute to a high-performance in photodetectors. LHPs also have high luminescence quantum yields. For solution-processed $\mathrm{MAPbI}_{3-\mathrm{x}} \mathrm{Cl}_{\mathrm{x}}$ crystalline films as an example, a high photoluminescence (PL) quantum efficiency up to $70 \%$ has been reported [31]. $\mathrm{MAPbI}_{3}$ films have been found to demonstrate an outstanding gain of $3200 \pm 830 \mathrm{~cm}^{-1}$, which is comparable to conventional light-emitting materials [32]. The high luminescence quantum yield along with the tunable band-gap, makes LHPs ideal candidates for applications including lasers and LEDs.
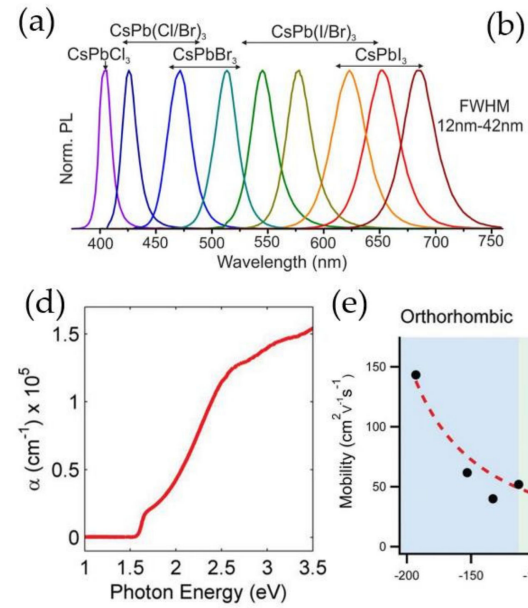

(e)

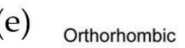

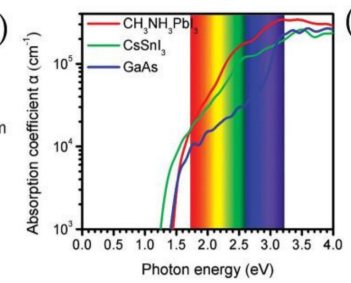

Photon energy $(\mathrm{eV})$

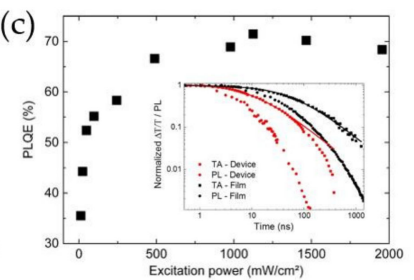

(f)

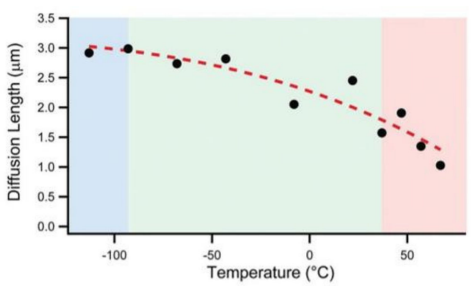

Figure 2. Optical and electrical properties of LHPs. (a) Representative photoluminescence (PL) spectra for $\mathrm{CsPbX}_{3} \mathrm{Y}_{3-\mathrm{z}}$, where $X$ and $Y$ represents different halide elements, demonstrating a wide wavelength tunability for LHP. Reprinted with permission from [33]. Copyright 2015 American Chemistry Society (b) The absorption coefficient $(\alpha)$ of $\mathrm{CH}_{3} \mathrm{NH}_{3} \mathrm{PbI}_{3}$ $\left(\mathrm{MAPbI}_{3}\right), \mathrm{CsSnI}_{3}$ and $\mathrm{GaAs}$. Reproduced with permission from [30].; published by Wiley, 2014. (c) The photoluminescence quantum efficiency (PLQE) of $\mathrm{MAPbI}_{3-\mathrm{x}} \mathrm{Cl}_{\mathrm{x}}$ films. The inset shows the normalized PL intensity (integrated from 1.71 to $1.57 \mathrm{eV}$ ) and the transient absorption (TA) signal versus time for device and film samples. Reprinted with permission from [31] Copyright 2014 American Chemistry Society. (d) Absorption coefficient of $\mathrm{MAPbI}_{3}$ perovskite films, for which the absorption onset is at $1.55 \mathrm{eV}$. Reproduced with permission from [32].; published by Wiley, 2015. (e,f) mobility and diffusion of $\mathrm{MAPbI}_{3}$. In both panels, the black dots represent experimental data, and the regions marked by different colors from left to right correspond to orthorhombic, tetragonal, and cubic phase, respectively. The dashed lines in (e) is $\mathrm{T}^{-3 / 2}$ dependence prediction for band-like transport, and in (f) is an eye-guide. Reproduced with permission from [34]; published by Wiley, 2015.

LHPs are found to have high carrier mobility, long diffusion length, and low traprelated recombination rates [35-37]. These properties govern carriers' transport dynamics which are important in applications such as photodetection. Carrier mobility and diffusion length are closely related to each other, and these two parameters show similar dependence on factors including crystalline quality and chemical composition [35]. The crystalline quality seems to be a dominant factor, and the mobility/diffusion length is much larger for single-crystal samples than its film counterparts. For instance, the hole mobility has been found to be $\sim 164 \mathrm{~cm}^{2} /(\mathrm{Vs})$ in solution-processed single-crystalline characterized using space charge limit current (SCLC) technique [38,39], which goes to $\sim 0.4 \mathrm{~cm}^{2} /(\mathrm{Vs})$ in poly- 
crystalline films [40]. The carrier diffusion length in $\mathrm{MAPbI}_{3}$ single crystals could be more than $175 \mu \mathrm{m}$ [39], which could be reduced to $0.1 \mu \mathrm{m}$ in $\mathrm{MAPbI}_{3}$ films [41]. Chemical composition tuning also enables the alteration of mobility and diffusion length. For instance, the diffusion length for $\mathrm{MAPbI}_{3-\mathrm{x}} \mathrm{Cl}_{\mathrm{x}}$ is more than $1 \mu \mathrm{m}$ [40], while in $\mathrm{CH}\left(\mathrm{NH}_{2}\right)_{2} \mathrm{PbI}_{3}$ $\left(\mathrm{FAPbI}_{3}\right)$ films the effective diffusion length for electrons and holes are $177 \pm 20 \mathrm{~nm}$ and $813 \pm 72 \mathrm{~nm}$, respectively [42]. When the film processing condition and procedures are optimized, the diffusion length could be further elongated [43,44]. The dependence mentioned above could be finally attributed to intrinsic factors such as Fröhlich interactions and extrinsic factors such as charge-carrier scattering by grain boundaries and dopants [45].

\subsection{Intrinsic Instability of $L H P$}

Although LHPs have novel properties leading to outstanding working performances in opto-electronic industry, the massive usage of the materials in practical occasions are mainly hindered by the severe instability of LHPs. As shown in Figure 3, moisture, oxygen, elevated temperature, and light radiation are found to induce material degradation quite easily [46-48]. As for moisture and oxygen which is generally not necessary for device function, the corresponding degradation could be generally dealt with by insulation. For instance, it is required that the preparation of LHP-based solar cells should be in a relatively low humidity level of $<1 \%$ atmosphere [49]. By careful encapsulation or introduction of hydrophobic contacts [50], device lifespan could be improved considerably. Unlike moisture and oxygen, heat is likely to accompany the device operation in some applications. The degree of heat-induced degradation is found to be dependent on chemical composition. For instance, while $\mathrm{MAPbI}_{3}$ will degrade at $85^{\circ} \mathrm{C}$ [51], $\mathrm{CsPbI}_{3}$ could endure much higher temperature, showing stability up to $300^{\circ} \mathrm{C}$ [52].
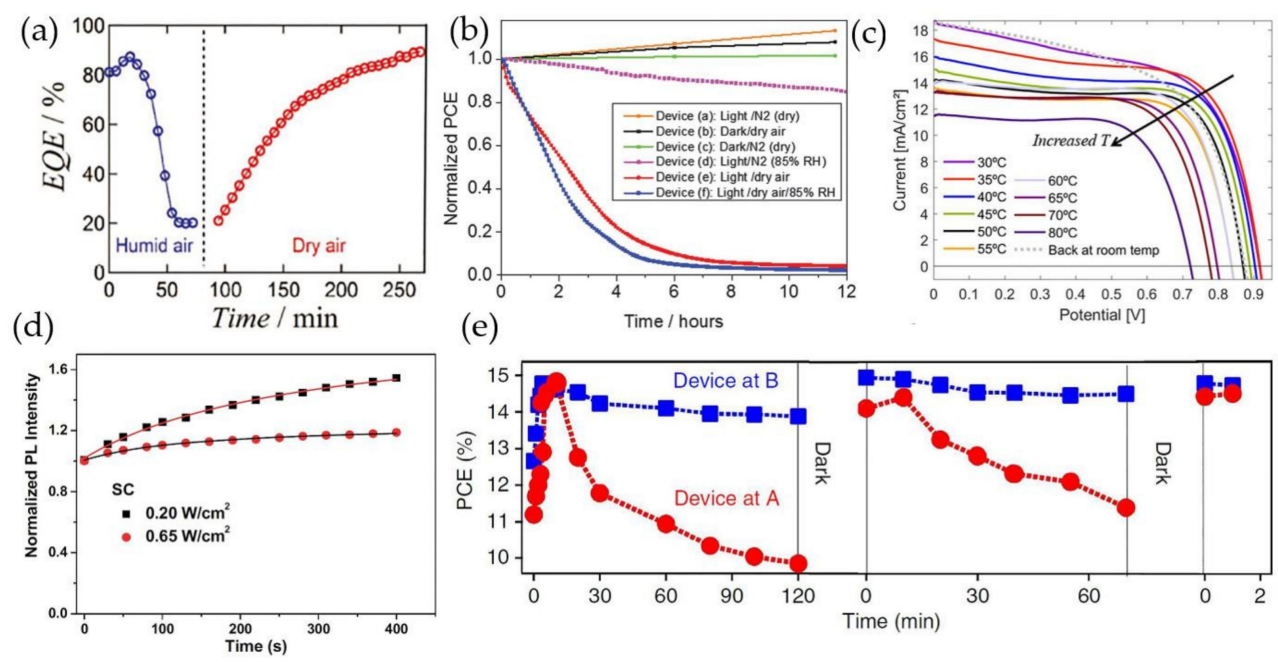

Figure 3. Instability of LHP induced by different environmental factors. (a) External quantum efficiency (EQE) as a function of exposure time to humid or dry air. Reproduced with permission from [53]; published by Wiley, 2016. (b) Evolution of the normalized power conversion efficiency (PCE) of $\mathrm{FTO} / \mathrm{cp}-\mathrm{TiO}_{2} / \mathrm{mp}-\mathrm{TiO}_{2} / \mathrm{MAPbI}_{3} /$ spiro-OMeTAD/Au devices in various environments. Illumination was performed with white LEDs equipped with ultraviolet (UV) filters. Reproduced with permission from [47]; published by The Royal Society of Chemistry, 2016. (c) I-V curves of a $\mathrm{MAPbI}_{3}$ Perovskite Solar Cells as a function of temperature. Reprinted with permission from [54]. Copyright 2016 American Chemistry Society. (d) PL intensities of the spin-coated $\mathrm{MAPbI}_{3}$ sample over time, under laser excitations at 0.2 and $0.65 \mathrm{~W} / \mathrm{cm}^{2}$, respectively. Reproduced with permission from [55]; published by Wiley, 2016. (e) The PCE evolution with time under 1-sun illumination and after resting the device in dark, when the device is stressed at point $\mathrm{A}$ (red circles, $\mathrm{J}=0, \mathrm{~V}=\mathrm{Voc}$ ) or at point B (blue squares, $\mathrm{J}=\mathrm{J}_{\mathrm{SC}}, \mathrm{V}=0$ ) between each data point. Reproduced with permission from [47]; published by Springer Nature, 2016. 
Light-induced degradation of LHP may be the most intractable problem, since light radiation is a necessity for most of the LHP-based devices to function properly. Researchers have found that the detailed degradation depend significantly on factors including illumination time, power density, and wavelength. When the device is exposed to relatively low power density for a short time, the so-called photo-curing effect is likely to occur, leading to substantial enhancements in PL intensity as well as devices' working performances [56,57]. However, the enhancements could not last long. With the further extension of illumination time, apparent degradation could be observed $[47,58,59]$. When the illumination power density increases even higher, the degradation accelerates, and structure transformation could be easily exhibited by characterization techniques such as Raman spectroscopy [60-64]. LHP may recover after being placed in dark for a certain period of time; however, the recovery reported varies from different research groups [47,58]. The illumination wavelength has been also found to have apparent influence on LHP's degradation. Both ultraviolet (UV) [65-68] and infrared (IR) light [58] has been found to accelerate the degradation of solar cells, attributed to different physical mechanisms. By now, people have proposed explanations such as ion-migration and light-induced trap states $[12,47,67,69-71]$, but no census has been reached yet. The light-induced degradation turns out to be a very complex process, and it is possible that the degradation involves more than one contributing mechanism simultaneously.

In a nutshell, LHP tends to degrade easily in environmental factors including humidity, oxygen, heat, and light. When the corresponding material is to be grown or the device to be designed and fabricated, people need to maintain a good awareness of the instability of LHP, so as to ensure that the LHP is not damaged during fabrication and stay undegraded as long as possible.

\section{The LHP Based Functional Devices}

\subsection{Lasers}

\subsubsection{Lasers and Factors Influencing Their Performances}

LHPs are ideal candidates for gain materials in next-generation lasers. By now, a diversity in different lasing configurations has been enjoyed, which could be referred to in Figure 4. As an instance, Saliba et al., 2016 put forward a general structuring approach for a LHP-based distributed feedback (DFB) laser by evaporating the $\mathrm{MAPbI}_{3}$ film onto a nanoimprinted polymer gratings with different pitches $(\Lambda)$ [72]. The laser emission wavelength could be altered in the range of $770-793 \mathrm{~nm}$ by tuning the grating periodicity. A threshold in the level of $\sim \mu \mathrm{J} / \mathrm{cm}^{2}$ has been found when pumped by a $532 \mathrm{~nm}$ nanosecond pulsed laser. Chen et al., on the other hand, reported a LHP photonic crystal (PhC) laser, fabricated by depositing the $\mathrm{MAPbI}_{3}$ thin films onto a 2D quartz $\mathrm{PhC}$ resonator [7]. In the PhC cavity, light-matter interaction could be enhanced via the in-plane distributed feedback, and single mode lasing could be achieved by appropriately matching the $\mathrm{PhC}$ band edge mode with the gain band of LHP. The device exhibited an output beam with a coherent and well-defined spatial profile, showing a small angular divergence $\left(<2^{\circ}\right)$ in the far-field pattern. The laser demonstrated a threshold of $68.5 \mu \mathrm{J} / \mathrm{cm}^{2}$ when pumped by a $532 \mathrm{~nm}$ laser with $270 \mathrm{ps}$ duration and showed a differential quantum efficiency of $35.8 \pm 5.4 \%$. By now, in addition to DFB lasers [8,72-76] and PhC lasers [2,7], LHP have also been utilized in lasers including whispering gallery mode (WGM) lasers [77], vertical cavity surface-emitting lasers (VCSEL) $[5,14,78,79]$, and so on. The detailed parameters regarding LHP-based lasers' performances are presented in Table 1. 
(a)

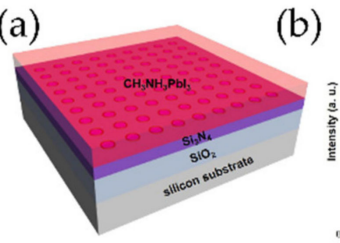

(e)

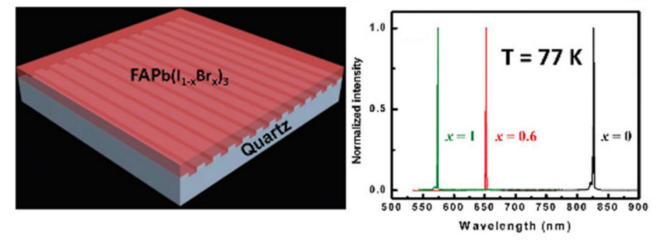

(c)

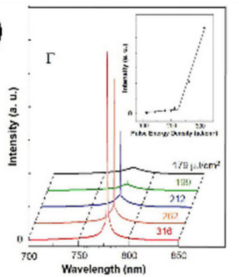

(f)

(g)
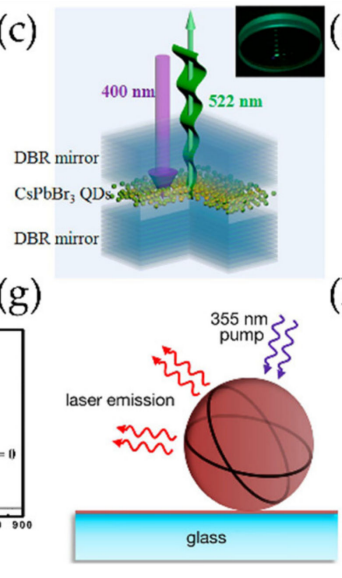

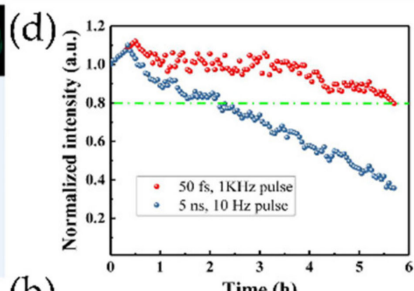

(h)

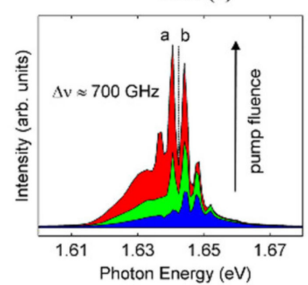

Figure 4. Lasing in LHP with various types of micro/nano structures. (a) Schematic diagram of a $\mathrm{MAPbI}_{3}$ photonic crystal $(\mathrm{PhC})$ band edge laser. (b) The lasing spectra versus the pump intensity, and the intensities were extracted and shown in the inset. Reprinted from [2], with the permission of AIP Publishing. (c) Schematic diagram of the $\mathrm{CsPbBr}_{3}$ quantum dot (QD) vertical cavity surface-emitting lasers (VCSEL) (Inset: a photograph of the device in operation.). (d) The stability characterization for the laser under nanosecond / femtosecond pump light, revealing a longer lifespan for the femtosecond pumping condition. Reprinted with permission from [5]. Copyright 2017 American Chemistry Society. (e) Schematic illustration of a LHP alloy distributed feedback (DFB) laser. (f) The lasing spectra with varying chemical compositions, at $77 \mathrm{~K}$. Reproduced with permission from [8]; published by Wiley, 2017. (g) Lasing in a $\mathrm{MAPbI}_{3}$-covered sphere resonator. (h) The emission spectra under different pump fluences. Reprinted with permission from [80]. Copyright 2014 American Chemistry Society.

Table 1. Device parameters for the lead halide perovskites (LHP-based Lasers).

\begin{tabular}{|c|c|c|c|c|c|c|}
\hline Material & Cavity & $\lambda_{\text {pump }}(\mathrm{nm})$ & Pulse Duration & $\lambda_{\text {lasing }}(\mathrm{nm})$ & $\mathbf{P}_{\text {th }}$ & $\Delta \lambda(\mathrm{nm})$ \\
\hline $\mathrm{MAPbI}_{3}[6]$ & $\begin{array}{c}\text { distributed } \\
\text { feedback (DFB) }\end{array}$ & 355 & $0.5 \mathrm{~ns}$ & 777.6 & $91 \pm 2 \mu \mathrm{J} / \mathrm{cm}^{2}$ & $<1.1$ \\
\hline- & - & 532 & $0.5 \mathrm{~ns}$ & - & $40 \pm 5 \mu \mathrm{J} / \mathrm{cm}^{2}$ & - \\
\hline $\mathrm{MAPbI}_{3}$ [81] & DFB & 445 & 920ns & 785 & $17 \mathrm{~kW} / \mathrm{cm}^{2}$ & 0.25 \\
\hline $\mathrm{MAPbI}_{3}[72]$ & DFB & 532 & $1 \mathrm{~ns}$ & 779 & $0.32 \mu \mathrm{J} / \mathrm{cm}^{2}$ & 2.2 \\
\hline $\mathrm{MAPbI}_{3}[74]$ & DFB & 355 & $0.9 \mathrm{~ns}$ & 784 & $110 \mu \mathrm{J} / \mathrm{cm}^{2}$ & $<0.4$ \\
\hline- & - & 515 & $200 \mathrm{fs}$ & - & $4 \mu \mathrm{J} / \mathrm{cm}^{2}$ & - \\
\hline $\mathrm{MAPbBr}_{3}$ [75] & DFB & 400 & $100 \mathrm{fs}$ & 541.6 & $2.3 \mu \mathrm{J} / \mathrm{cm}^{2}$ & - \\
\hline $\mathrm{MAPbI}_{3}[73]$ & DFB & 532 & $1 \mathrm{~ns}$ & 786.5 & $120 \mathrm{~kW} / \mathrm{cm}^{2}$ & 0.2 \\
\hline $\mathrm{MAPbI}_{3}[76]$ & DFB & 532 & $1 \mathrm{~ns}$ & 783 & $270 \mathrm{~kW} / \mathrm{cm}^{2}$ & 0.4 \\
\hline $\mathrm{FAPbI}_{3}[8]$ & DFB & 532 & $400 \mathrm{ps}$ & 825 & - & - \\
\hline $\mathrm{FAPb}\left(\mathrm{I}_{0.4} \mathrm{Br}_{0.6}\right)_{3}[8]$ & - & - & - & 650 & $3.5 \mu \mathrm{J} / \mathrm{cm}^{2}$ & - \\
\hline $\mathrm{FAPbBr}_{3}[8]$ & - & - & - & 575 & - & - \\
\hline $\mathrm{MAPbI}_{3}[2]$ & $\mathrm{PhC}$ & 532 & $400 \mathrm{ps}$ & 780 & $200 \mu \mathrm{J} / \mathrm{cm}^{2}$ & - \\
\hline $\mathrm{MAPbI}_{3}$ [7] & $\mathrm{PhC}$ & 532 & $270 \mathrm{ps}$ & 788.1 & $68.5 \mu \mathrm{J} / \mathrm{cm}^{2}$ & 0.24 \\
\hline $\mathrm{CsPbBr}_{3}[5]$ & DBR & 400 & $50 \mathrm{fs}$ & 522 & $0.39 \mu \mathrm{J} / \mathrm{cm}^{2}$ & 0.9 \\
\hline- & - & 355 & $5 \mathrm{~ns}$ & 522 & $98 \mu \mathrm{J} / \mathrm{cm}^{2}$ & - \\
\hline $\mathrm{MAPbI}_{3}$ [14] & DBR & 532 & $0.34 \mathrm{~ns}$ & 778.4 & $\begin{array}{l}7.6 \pm 0.6 \\
\mu \mathrm{J} / \mathrm{cm}^{2}\end{array}$ & 0.24 \\
\hline- & - & 532 & $5 \mathrm{~ns}$ & 778.4 & $\begin{array}{c}113.9 \pm 15 \\
\mu \mathrm{J} / \mathrm{cm}^{2}\end{array}$ & 0.24 \\
\hline $\mathrm{CsPbCl}_{3}[82]$ & DBR & 375 & $100 \mathrm{fs}$ & 428 & $12 \mu \mathrm{J} / \mathrm{cm}^{2}$ & 0.5 \\
\hline $\mathrm{CsPbBr}_{3}[79]$ & DBR & 400 & $100 \mathrm{fs}$ & 510 & $11 \mu \mathrm{J} / \mathrm{cm}^{2}$ & 0.6 \\
\hline- & - & 400 & $5 \mathrm{~ns}$ & - & $900 \mu \mathrm{J} / \mathrm{cm}^{2}$ & - \\
\hline $\mathrm{MAPbI}_{3}[78]$ & DBR & 530 & $4 \mathrm{~ns}$ & 780 & $15.3 \mu \mathrm{J} / \mathrm{cm}^{2}$ & 4.9 \\
\hline $\mathrm{MAPbI}_{3}[80]$ & sphere & 355 & $2 \mathrm{~ns}$ & 756 & $75 \pm 11 \mu \mathrm{J} / \mathrm{cm}^{2}$ & - \\
\hline $\mathrm{MAPbI}_{3}$ [83] & FP & 400 & $120 \mathrm{fs}$ & 778 & $13.5 \mu \mathrm{J} / \mathrm{cm}^{2}$ & 5.16 \\
\hline
\end{tabular}


Table 1. Cont.

\begin{tabular}{|c|c|c|c|c|c|c|}
\hline Material & Cavity & $\lambda_{\text {pump }}(\mathrm{nm})$ & Pulse Duration & $\lambda_{\text {lasing }}(\mathrm{nm})$ & $\mathbf{P}_{\text {th }}$ & $\Delta \lambda(\mathrm{nm})$ \\
\hline $\mathrm{CsPbBr}_{3}$ [84] & WGM & 400 & $100 \mathrm{fs}$ & 543 & $7.24 \mu \mathrm{J} / \mathrm{cm}^{2}$ & - \\
\hline $\mathrm{MAPbBr}_{3}$ [85] & $\mathrm{FP}$ & - & - & 553.2 & $106.6 \mu \mathrm{J} / \mathrm{cm}^{2}$ & - \\
\hline $\mathrm{MAPbI}_{3}[86]$ & WGM & 400 & 50 & 783 & $11 \mu \mathrm{J} / \mathrm{cm}^{2}$ & 0.64 \\
\hline $\mathrm{MAPbBr}_{3}$ [87] & $\mathrm{FP}$ & - & - & 553 & $4.7 \mu \mathrm{J} / \mathrm{cm}^{2}$ & - \\
\hline $\mathrm{MAPbBr}_{3}[88]$ & $\mathrm{FP}$ & 400 & 100 & 550 & $2.5 \mu \mathrm{J} / \mathrm{cm}^{2}$ & - \\
\hline
\end{tabular}

The material property, of course, could influence the laser performance in more than one aspect. Mathies et al. reported an inkjet-printed LHP DFB laser [76], by using inkjet printing technique instead of the spin-coating method, to achieve the digital deposition of arbitrary shaped layers. As a trade-off, however, the device exhibited a higher lasing threshold and an increased instability as compared to the spin-coated devices, which was attributed to the remaining roughness in the LHP film [89] and remaining precursor $\mathrm{PbI}_{2}$ in the film [90]. LHP-based laser threshold has been found to be reduced when the pump pulse duration was shortened [74]: for instance, the lasing threshold has been found to be $110 \mu \mathrm{J} / \mathrm{cm}^{2}$ when the pulse duration is $0.9 \mathrm{~ns}$, which goes to $4 \mu \mathrm{J} / \mathrm{cm}^{2}$ when the duration is reduced to $200 \mathrm{fs}$. This reduction was finally attributed to the fact that the pump duration (200 fs) is shorter than the electron-hole recombination lifetime in LHP. The threshold could also be lower with a decreasing in defect density and scattering inside the LHP, which could be possibly achieved when the single-crystal LHP is used instead of the polycrystalline counterparts [75].

A careful design and optimization of the device configuration provides another route for performance improvement. Stranks et al. proposed an idea of constructing the vertical cavity structure using a cholesteric liquid crystal (CLC) as the reflector [78]. The CLC could redirect the emission that propagates along the out-of-plane and oblique paths back into the bulk to increase the optical length, thus resulting in a lower lasing threshold. The device without CLC would exhibit a broad photoluminescence (PL) even at high excitation fluence of $600 \mu \mathrm{J} / \mathrm{cm}^{2}$; in contrast, the device with the CLC showed the transformation from PL to ASE at a low threshold of $15.3 \mu \mathrm{J} / \mathrm{cm}^{2}$. Enhancement in optical confinement is another factor leads to performance improvement. Liu et al. have deliberately inserted a layer of micropatterned Boron nitride (BN) between LHP microplatelet and the substrate in the WGM laser [86]. The introduction of BN could provide an epitaxial intermediary between the LHP and the substrate and also enable a better optical confinement in lasing due to the large bandgap in BN. In addition, metals have also been introduced to excite plasmonic effects to improve device performances. By hybridization of surface plasmon polaritons with the gain medium, the breaking-down of diffraction limit could be achieved. $\mathrm{Yu}$ et al. put forward a plasmonic LHP laser by placing a $\mathrm{MAPbI}_{3}$ single crystal nanowire onto a sliver substrate [83]. This plasmonic laser enables optical modes of free diffraction limit on a nanometer scale. Pumped by a $400 \mathrm{~nm}$ laser with a pulse duration of $120 \mathrm{fs}$, the laser demonstrated a relatively low threshold of $13.5 \mu \mathrm{J} / \mathrm{cm}^{2}$ and notably a good temperature tolerance up to $43.6{ }^{\circ} \mathrm{C}$. Wang et al. has developed a way to deposit an uniform aluminum nanoparticles onto the $\mathrm{CsPbBr}_{3}$ microrods [84], with a lithography-free fabrication technique to avoid further damage to the LHP layer. Through optimization of deposition time, the plasmonic resonances of the aluminum nanoparticles array could be tuned to cover the emission wavelength range of $\mathrm{CsPbBr}_{3}$ and modify the surface density of states on it. As a result, the laser threshold was reduced by more than $20 \%$, and the output intensities are enhanced by more than an order of magnitude.

In addition to working performance, the device stability is also a big concern to researchers. A LHP with a higher stability could be used instead of the less-stable LHP to improve the device stability: for instance, a LHP VCSEL based on CsPbBr 3 quantum dot (QD) or nanocrystals has been proposed, intended to achieve longer lifespan since $\mathrm{CsPbBr}_{3}$ $\mathrm{QD}$ is more stable than $\mathrm{MAPbI}_{3}[5,79]$. Working conditions, such as pulse duration, have 
also been found to influence the stability, as shown in lasers with different optical cavities. As compared to the fs-pulse pumping, ns-pumping tends to lead to faster degradation, which has been attributed to laser heating of larger durations.

\subsubsection{Laser Array}

In addition to individual micro/nano lasers as functional devices in integrated optical circuits, the LHP-based laser arrays have also been proposed $[7,77,86-88]$, some of which are shown in Figure 5. Uniform lasing in LHP microlaser array has been achieved on a grating of semiconductor or metals $[87,88]$, with the LHP microstructures (such as $\mathrm{MAPbBr}_{3}$ microwires and microplates) utilized. The lasing in the transverse plane of LHP nanostructures was utilized, to achieve a higher quality factor (Q-factor) and narrower line width. Since the transverse size of the LHPs' microstructures are highly uniform, the lasing wavelength from the individual lasers could be unified. When being transferred onto the silicon grating, for instance, the single-crystalline $\mathrm{MAPbBr}_{3}$ microwire or microplate was divided into tiny subunits: the part of LHP on top of the silicon strips would not support lasing actions, while the air-suspending LHP part allow transverse lasing. The smallest subunit period of $800 \mathrm{~nm}$ has been achieved. These laser arrays with a high density of individual lasers as well as uniform lasing is highly desired to applications such as high throughput bio-sensing, ultrahigh resolution imaging, and medical diagnosis.

\section{(a)}
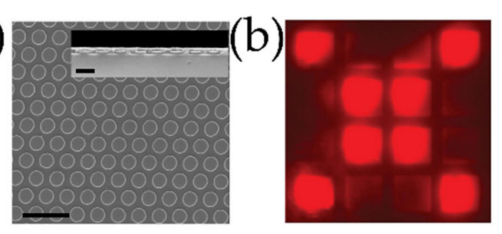

(c)

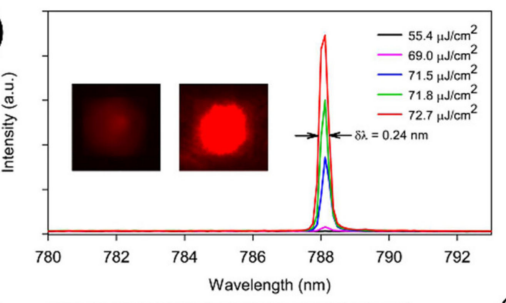

(f)

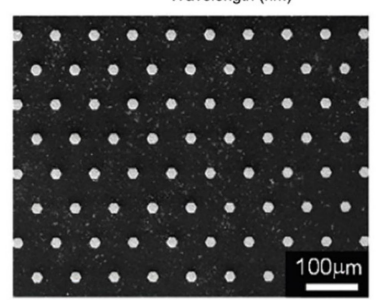

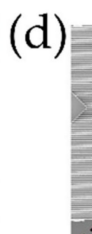
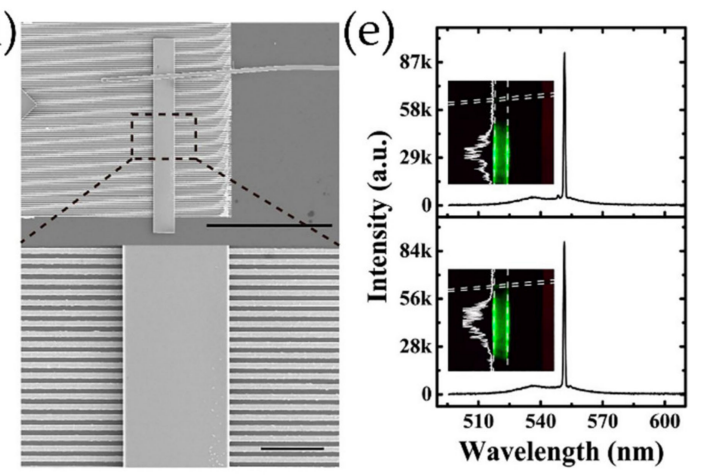

(g)

(h)

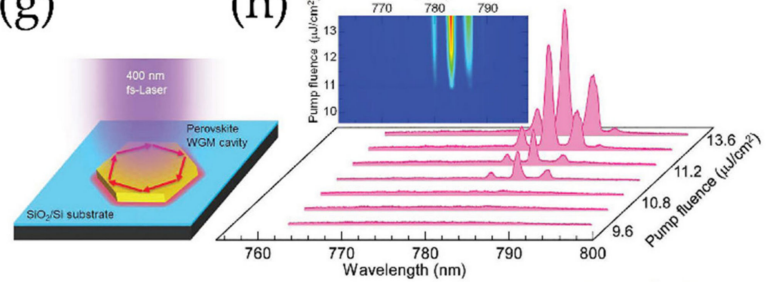

Figure 5. LHP-based laser array. (a) The scanning electron microscope (SEM) image of the photonic crystal $(\mathrm{PhC})$ with the deposited perovskite and $(\mathbf{b})$ the photographic image of the 16 pixels laser array. (c) The emission spectra with varying excitation fluence (Inset: photographic images taken by an adjacent infrared (IR) camera with excitation below (left) and above (right) threshold, respectively). Reprinted with permission from [7]. Copyright 2016 American Chemistry Society. (d) The SEM image of the LHP nanoribbon on the Au grating. (e) The emission spectra and fluorescent microscope images taken from different positions of the nanolaser array, indicating a uniform lasing of the array. Reprinted with permission from [88]. Copyright 2017 American Chemistry Society. (f) The SEM image of the lead halide perovskite/h-Boron nitride (LHP/h-BN) platelet array. (g) schematic illustration on lasing in the whispering gallery mode (WGM) cavity and (h) the emission spectra evolution under different pump intensities. Reproduced with permission from [86]; published by Wiley, 2016. 


\subsection{Photodetectors}

Photodetectors are devices that convert optical signals to electrical signals, which are one of the key components used in areas including communication, sensing, imaging, and computation. People have proposed photodetectors by combining LHP with 2D and 1D materials to realize high performance and broad working range. As presented in Figure 6, bending of the electronic band at the interface is the key to realize high performance photodetection. By combining LHP with the other species of material, enhancement in the effective absorption coefficient and/or absorption bandwidth could be achieved. The device performances for some of the recent LHP photodetectors are presented in Figure 7, and the parameters are summarized in Table 2.

(a)

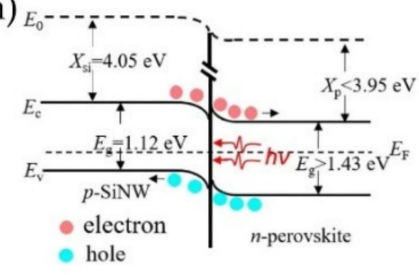

(b)

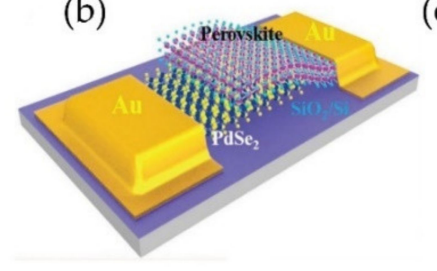

(c)

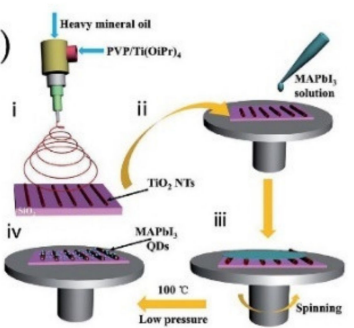

Figure 6. (a) The bending of energy band at the interface of the LHP based photodetector. Reprinted with the permission from [9]. Copyright 2018 American Chemistry Society. (b) Schematic illustration of a hybrid photodetector by combining perovskite with the 2D PdSe 2 . Reproduced with permission from [91]; published by Wiley, 2019. (c) The fabrication process for a $\mathrm{LHP} / \mathrm{TiO}_{2}$ nanotubes (NTs) photodetector. Reproduced with permission from [81]; published by Wiley, 2017.

(a)

(b)
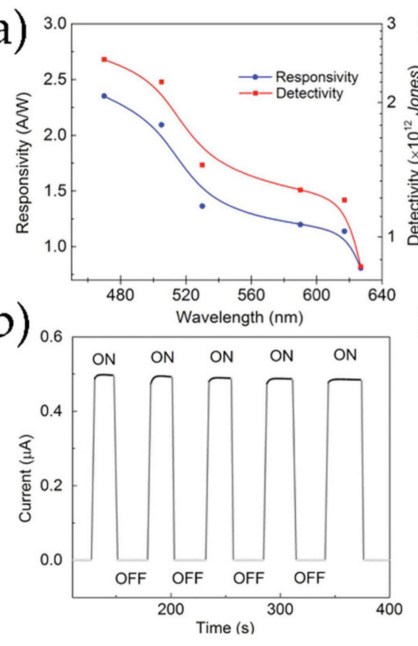

(c)
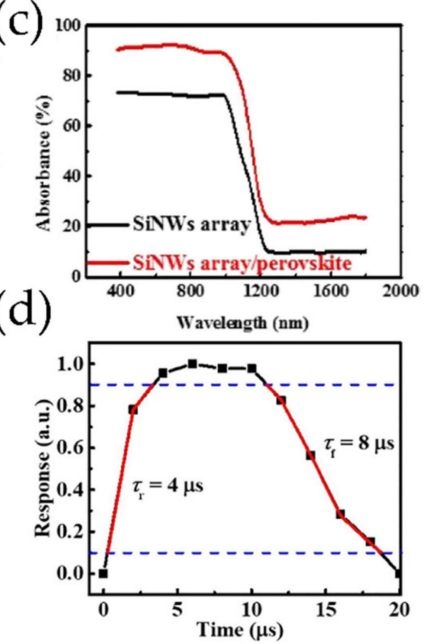

(e)

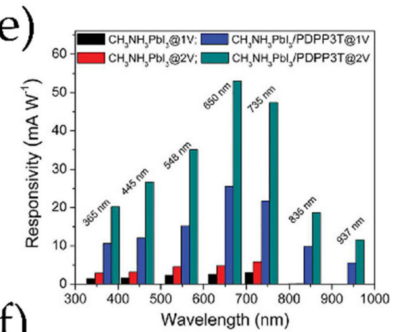

(f)

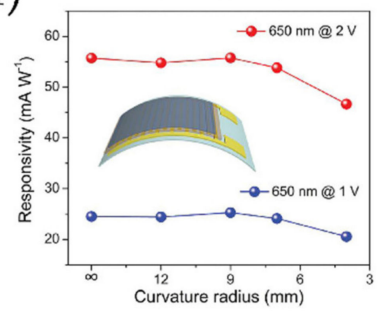

Figure 7. Device performance of LHP photodetectors. (a) Responsivity (R) and detectivity ( $\mathrm{D}^{*}$ ) of the $\mathrm{WS}_{2}$ /perovskite photodetector and (b) the corresponding time-dependent photocurrent response showing a stable operation. Reproduced with permission from [92]; published by Wiley, 2016. (c) Comparison on the absorption of the $\mathrm{Si} \mathrm{NWs}$ array/Cs-doped $\mathrm{FAPbI}_{3}$ heterostructure and pure Si NWs array; (d) The fast response of the device. Reprinted with the permission from [9]. Copyright 2018 American Chemistry Society. (e) Comparison on $\mathrm{R}$ of the $\mathrm{MAPbI}_{3}$ and $\mathrm{MAPbI}_{3} / \mathrm{PDPP} \mathrm{T}$ composite photodetectors in the ultraviolet-visible-near infrared (UV-vis-NIR) region indicating an improved performance of the hybrid structure. (f) $\mathrm{R}$ versus bending curvature radium of the $\mathrm{MAPbI}_{3} / \mathrm{PDPP} 3 \mathrm{~T}$ composite photodetector demonstrating a good flexibility of the device. Reproduced with permission from [93]; published by Wiley, 2016. 
Table 2. Device parameters for LHP-based photodetectors.

\begin{tabular}{|c|c|c|c|c|c|c|}
\hline Materials & Pump (nm) & $\mathrm{R}(\mathrm{A} / \mathrm{W})$ & $\mathrm{D} *$ (Jones) & Rise Time & Decay Time & $\begin{array}{c}\text { Response } \\
\text { Range (nm) }\end{array}$ \\
\hline $\mathrm{MAPbI}_{3} /$ graphene [94] & 520 & 180 & $>10^{9}$ & $87 \mathrm{~ms}$ & $540 \mathrm{~ms}$ & $\begin{array}{c}\text { visible-near } \\
\text { infrared } \\
\text { (Vis-NIR) }\end{array}$ \\
\hline \multirow[t]{4}{*}{$\mathrm{MAPbI}_{3} / \mathrm{MoS}_{2}$ [95] } & 520 & $2.12 \times 10^{4}$ & $1.38 \times 10^{10}$ & $6.17 \mathrm{~s}$ & $4.5 \mathrm{~s}$ & Vis-NIR \\
\hline & 655 & $8.24 \times 10^{3}$ & $5.37 \times 10^{9}$ & - & - & \\
\hline & 785 & $1.02 \times 10^{4}$ & $6.66 \times 10^{8}$ & - & - & \\
\hline & 850 & $1.11 \times 10^{2}$ & $7.93 \times 10^{7}$ & - & - & \\
\hline $\mathrm{MAPbI}_{3} / \mathrm{WS}_{2}$ [92] & 505 & 2.4 & $2 \times 10^{12}$ & $2.7 \mathrm{~ms}$ & $7.5 \mathrm{~ms}$ & Vis \\
\hline \multirow{2}{*}{$\mathrm{MAPbI}_{3} / \mathrm{TiO}_{2}[81]$} & 350 & 1.3 & $2.5 \times 10^{12}$ & $2 \mathrm{~s}$ & $1 \mathrm{~s}$ & $300-800$ \\
\hline & 700 & 0.2 & $3.8 \times 10^{11}$ & $7 \mathrm{~s}$ & $4 \mathrm{~s}$ & \\
\hline $\mathrm{MAPbI}_{3} / \mathrm{TiO}_{2}[90]$ & 494 & 0.85 & $7.8 \times 10^{10}$ & - & - & UV-Vis \\
\hline $\mathrm{FAPbI}_{3} /$ silicon [9] & 850 & 0.844 & $3.2 \times 10^{11}$ & $4 \mu \mathrm{s}$ & $8 \mu \mathrm{s}$ & $300-1200$ \\
\hline $\mathrm{MAPbI}_{3} / \mathrm{ZnO}[96]$ & 325 & 0.0083 & $3.2 \times 10^{10}$ & $53 \mu \mathrm{s}$ & $63 \mu \mathrm{s}$ & - \\
\hline $\mathrm{MAPbI}_{3} / \mathrm{ZnO}[18]$ & 1357 & 0.22 & $9.3 \times 10^{9}$ & $0.3 \mathrm{~s}$ & $0.8 \mathrm{~s}$ & 250-1357 \\
\hline $\mathrm{FAPbI}_{3} / \mathrm{PdSe}_{2}[91]$ & 808 & 0.313 & $2.72 \times 10^{13}$ & $3.5 \mu \mathrm{s}$ & $4 \mu \mathrm{s}$ & 200-1550 \\
\hline \multirow{2}{*}{$\mathrm{MAPbI}_{3} / \mathrm{PdSe}$ [97] } & 300 & 1.2 & $3.3 \times 10^{7}$ & - & - & $300-1500$ \\
\hline & 808 & - & - & $2.5 \mathrm{~ms}$ & $3 \mathrm{~ms}$ & \\
\hline \multirow[t]{3}{*}{$\mathrm{MAPbI}_{3-\mathrm{x}} \mathrm{Cl}_{\mathrm{x}} / \mathrm{BP}[20]$} & 370 & $5.5 \times 10^{6}$ & $4.6 \times 10^{13}$ & - & - & $350-1200$ \\
\hline & 598 & $1.1 \times 10^{7}$ & $9.2 \times 10^{13}$ & $8 \mathrm{~ms}$ & $17 \mathrm{~ms}$ & \\
\hline & 895 & $5.2 \times 10^{5}$ & $4.3 \times 10^{12}$ & - & - & \\
\hline $\mathrm{MAPbI}_{3} / \mathrm{WSe}_{2}[98]$ & 532 & 110 & $2.2 \times 10^{11}$ & - & - & - \\
\hline $\mathrm{FAPbI}_{3} / \mathrm{PtSe}_{2}[99]$ & 808 & 0.118 & $2.91 \times 10^{12}$ & $78 \mathrm{~ns}$ & $60 \mathrm{~ns}$ & $300-1200$ \\
\hline $\begin{array}{l}\mathrm{MAPbI}_{3-\mathrm{x}} \mathrm{Cl}_{\mathrm{x}} / \text { poly-(3,4- } \\
\text { ethylenedioxythiophene): } \\
\text { poly(styrenesulfonate) } \\
\text { (PEDOT:PSS) [100] }\end{array}$ & 598 & $1.91 \times 10^{9}$ & $1.4 \times 10^{14}$ & $4.5 \mathrm{~s}$ & $57.5 \mathrm{~s}$ & Vis-NIR \\
\hline- & 895 & $7.6 \times 10^{8}$ & $5.6 \times 10^{13}$ & - & - & \\
\hline $\mathrm{MAPbI}_{3} / \mathrm{PDPP3T} \mathrm{[93]}$ & 365 & 0.0107 & $6.1 \times 10^{9}$ & - & - & UV-NIR \\
\hline- & 650 & 0.0255 & $1.5 \times 10^{10}$ & - & - & \\
\hline- & 835 & 0.154 & $8.8 \times 10^{10}$ & - & - & \\
\hline- & 937 & 0.0055 & $3.2 \times 10^{9}$ & - & - & \\
\hline $\mathrm{CsPbBr}_{3} / \mathrm{MoS}_{2}[19]$ & 442 & 4.4 & $2.5 \times 10^{10}$ & $0.72 \mathrm{~ms}$ & $1.01 \mathrm{~ms}$ & UV-Vis \\
\hline $\mathrm{MAPbI}_{3} / 1 \mathrm{~T}-\mathrm{MoS}_{2}[101]$ & 500 & $3.1 \times 10^{3}$ & $7 \times 10^{11}$ & $0.45 \mathrm{~s}$ & $0.75 \mathrm{~s}$ & Vis-NIR \\
\hline $\mathrm{MAPbI}_{3} / 2 \mathrm{H}-\mathrm{MoS}_{2}[101]$ & 500 & 142 & $2.6 \times 10^{11}$ & $<25 \mathrm{~ms}$ & $<50 \mathrm{~ms}$ & \\
\hline $\mathrm{MAPbI}_{3}$ /graphene/Au [102] & 532 & $2 \times 10^{3}$ & - & $1.5 \mathrm{~s}$ & - & - \\
\hline
\end{tabular}

${ }^{*} \mathrm{R}$ : responsivity, $\mathrm{D}^{*}$ : detectivity.

\subsubsection{Photodetectors by Combining LHP with the 2D Materials}

The 2D materials have been frequently used in LHP hybrid photodetectors. The 2D materials such as graphene and transition metal dichalcogenides (TMDCs), although possessing superior high quantum efficiency and photoresponsivity, are inferior at absorbing sufficient light due to their ultrathin nature. LHPs, on the other hand, are materials with high absorption rate, not to mention the other advantages including the long electron-hole diffusion length and ambipolar charge transport. By combining LHP with 2D materials, such as graphene and TMDCs, high-level performance could be achieved.

Graphene is a zero-bandgap material and exhibits a broadband absorption. However, the ultra-thin nature as well as its fast recombination rate hinder its practical usage [103]. Lee et al. have proposed a hybrid photodetector by combining $\mathrm{MAPbI}_{3}$ with graphene [94]. Efficient charge transfer from the graphene layer to LHP layer was enabled, and the hybrid device showed broad absorption band and large absorption cross-section simultaneously. Light detection in the range of $400-850 \mathrm{~nm}$ was achieved: at $520 \mathrm{~nm}$ illumination with $1 \mu \mathrm{W}$ power, the device photoresponsivity was $180 \mathrm{~A} / \mathrm{W}$, and the detectivity was $10^{9}$ Jones. The photoresponsivity was deduced to be $\sim 10^{6} \mathrm{~A} / \mathrm{W}$ at $1 \mathrm{pW}$, being much larger than the $\mathrm{ZnO}$-based photodetectors [104]. While being in $\sim \mu \mathrm{A}$ level in graphene-only devices, the 
photocurrent has been enhanced to mA level in the hybrid devices, when the incident wavelength is shorter than $800 \mathrm{~nm}$. To further improve the graphene/LHP device performance, people have proposed the idea of inserting gold nanoparticles (Au-NPs) [102]. Through the surface plasmonic effect of the Au-NPs, near-field of LHP could be enhanced which leads to a larger absorption cross-section and ultimately photodetection performance. The responsivity, for instance, is almost twice higher in the hybrid device with Au-NPs than the device without Au-NPs insertion.

As another type of photodetection materials, TMDCs also suffer from the low-absorption efficiency. Kang et al. reported a $\mathrm{MoS}_{2} / \mathrm{LHP}$ hybrid photodetectors working in 520-850 nm range [95]. The LHP layer could absorb light until $800 \mathrm{~nm}$, beyond which the light is only absorbed by the $\mathrm{MoS}_{2}$ layer. It is found that by using the LHP layer as the main absorber, the photoresponsivity could be enhanced by more than 7 times (from 636 to $4.9 \times 10^{3} \mathrm{~A} / \mathrm{W}$ ) and the detectivity by more than 5.7 times (from $1.53 \times 10^{9}$ to $8.76 \times 10^{9}$ Jones), respectively, when compared to the $\mathrm{MoS}_{2}$-only device under $520 \mathrm{~nm}$ laser illumination. The enhancement disappeared at $850 \mathrm{~nm}$, at which the LHP is unable to absorb the incident light. $\mathrm{CsPbBr}_{3}$ nanosheets has also been used with $\mathrm{MoS}_{2}$ to form heterostructure. The utilization of $\mathrm{CsPBBr}_{3}$ nanosheets instead of the organic LHP counterpart could possibly increase the device lifespan but also result in the limitation of working band range due to the much larger bandgap in $\mathrm{CsPbBr}_{3}$ [19].

However, since the high responsivities and gains are dependent on long carrier lifetimes, it is hard to demand a rapid response in these devices. In order to achieve both high responsivity and response speed, Zou et al. proposed a Schottky barrier controlled black phosphorus (BP)/LHP phototransistor [20]. Thanks to the high electric field near the Schottky barrier, the photo-generated carriers could be rapidly extracted which led to fast response speed. The device demonstrated a high responsivity up to $10^{8} \mathrm{~A} / \mathrm{W}$ and a detectivity up to $9 \times 10^{13}$ Jones, with a short response time of $\sim 10 \mathrm{~ms}$. It is also noteworthy that under $895 \mathrm{~nm}$ near infrared (NIR) light illumination, which is beyond the absorption edge of LHP, a high responsivity of $5.2 \times 10^{5} \mathrm{~A} / \mathrm{W}$ is achieved, which is attributed to the carriers excited from the valence band to the trap states in the LHP layer. Zeng et al. [91] reported a $\mathrm{PdSe}_{2} / \mathrm{FA}_{0.85} \mathrm{Cs}_{0.15} \mathrm{PbI}_{3}$ Schottky junction broadband photodetector, which has an expressive optical response in a broadband of 200 to $1550 \mathrm{~nm}$, and the rise/decay time was found to be $3.5 \mu$ s and $4 \mu$ s, respectively. In addition to the high responsivity and detectivity exhibited by the photodetector, the device demonstrated a high polarization sensitivity of 6.04, due to the strong anisotropy in the 2D PdSe 2 crystal structure. Zhang et al. proposed a $\mathrm{PtSe}_{2} / \mathrm{Cs}$-doped $\mathrm{FAPbI}_{3}$ photodetector, which showed a wideband response from 300 to $1200 \mathrm{~nm}$ [99]. The ultra-fast response speed is also impressive, with the rise and decay time being 78 and 60 ns, respectively, which is among the best results reported for LHP-detectors $[105,106]$. This ultrafast response was attributed to factors including the built-in electric field at the heterostructure interface [107], the electrical properties of both LHP and $\mathrm{PtSe}_{2}$, and the reduced trap density in $\mathrm{Cs}$-doped $\mathrm{FAPbI}_{3}$ as compared to the other LHPs [108]. When the species of material is determined, the specific material quality could affect the device performances. Carrier traps, for instance, possibly lead to the reduction in photoresponsivity and detectivity. By reducing the trap density in the 2D materials through laser healing, the performance of a $\mathrm{WSe}_{2} / \mathrm{LHP}$ photodetector could be improved [98].

\subsubsection{Photodetectors by Combining LHP with 1D Materials}

In addition to $2 \mathrm{D}$ materials, LHP has also been combined with $1 \mathrm{D}$ materials such as nanotubes and nanowires. These 1D structures with large surface-to-volume ratio enable prolonged charge carrier lifetime, increased interfacial area, and suppressed light reflection, which is preferential for photodetection $[9,109]$. As one example, $\mathrm{TiO}_{2}$ nanotubes (NTs) or nanorods (NRs) have been utilized in photodetection recently [109], but the application has been limited to UV region due to its large bandgap. LHPs are thus used to combine with $\mathrm{TiO}_{2}$ to broaden the effective absorption band covering the UV and visible range [81,90]. In a $\mathrm{MAPbBr}_{3} \mathrm{QDs} / \mathrm{TiO}_{2} \mathrm{NTs}$ device [81], it is found that both the responsivity and detectivity 
in the visible range were increased considerably as compared to the NT-only device. In addition, a hybrid device based on $\mathrm{TiO}_{2} \mathrm{NRs}$ and $\mathrm{MAPbI}_{3}$ has been found to exhibit selfpowered characteristics at UV illumination, demonstrating a current of $15 \mu \mathrm{A}$ at $0 \mathrm{~V}$ [90]. This self-powered characteristic has been attributed to the blocking of electrons from LHP to anode by the HTM layer. Liu et al. [9] reported a silicon/LHP core-shell photodetector by depositing a layer of $\mathrm{Cs}$-doped $\mathrm{FAPbI}_{3}$ onto a silicon nanowire arrays, and the device was also found to be self-powered. When the bias was set to be $-0.9 \mathrm{~V}$, the performance could be further improved to show a high responsivity of $844.33 \mathrm{~mA} / \mathrm{W}$ and detectivity of $3.2 \times 10^{11}$ Jones. The device was swift in response, demonstrating a rise and decay time of $4 \mu \mathrm{s}$ and $8 \mu$ s respectively, very close to the commercial silicon photodiodes [110]. Alwadai et al. have proposed a photodetector combining LHP and Ga-doped ZnO NRs [18], which demonstrates a high-performance comparable to commercial IR detectors [111], and a wideband detection range from 250 to $1357 \mathrm{~nm}$. This IR detection ability was enabled by the intraband transition in LHP, and a Fano-like transition was observed in the IR range of the absorption spectra.

\subsubsection{Flexible Photodetectors}

Due to the ease of combining LHP with other materials, hybrid detectors with good flexibility have also been developed. Xie et al. reported a $\mathrm{MAPbI}_{3-\mathrm{x}} \mathrm{Cl}_{\mathrm{x}}$ lead halide perovskite/poly-(3,4-ethylenedioxythiophene):poly(styrenesulfonate) (LHP/PEDOT:PSS) vertical photodetector which maintained a good performance after being bent to a radius of $7 \mathrm{~mm}$ for 300 times, covering the wavelength range from UV to NIR [100]. The responsivities were in the level of $\sim 10^{9} \mathrm{~A} / \mathrm{W}$ and detectivities in the level of $\sim 10^{14}$ Jones [100]. Another flexible UV-NIR photodetector was put forward by Chen et al., in which a conjugatedpolymer (PDPP3T) is used in collaboration with LHP [93]. The two materials could complement each other very well: the polymer could be utilized to broaden the response band of LHP, while the presence of the LHP heterostructure leads to longer carrier diffusion length and enhanced carrier separation; in addition, the PDPP3T layer is found to resist moisture and oxidization in the LHP layer. After 1000 cycles bending/straitening to a curvature radius of $7 \mathrm{~mm}$, a retention of $90 \%$ or $85 \%$ of the responsivity was found under $650 \mathrm{~nm}$ or $835 \mathrm{~nm}$ illumination, respectively, demonstrating a good flexibility.

\subsection{Modulators}

Modulators and switches are common optical components found in integrated optical circuits. These days, LHP have been utilized to construct modulators or switches working in THz range, for which the corresponding working principle is presented in Figure 8. The light modulation or switching by LHP hybrid devices are based on the THz absorption by charge carriers. By combining LHP with a proper material (for instance, silicon has been frequently used), a heterostructure is produced, of which the electronic structure bends at the interface. When pump light is turned on, photogenerated carriers are to be excited and tend to drift to the interface and accumulate there. When the $\mathrm{THz}$ waves are incident at the devices, the wave will be attenuated by the carriers, through mechanisms including electron-hole scattering, electron-phonon scattering, and electron-impurity scattering [112]. The actual absorption coefficient of the device changes in correspondence to pump laser. Consequently, the intensity of the incident $\mathrm{THz}$ waves is modulated. In Table 3, the performance from some of the recent $\mathrm{LHP} \mathrm{THz}$ modulators is presented. 
(a)

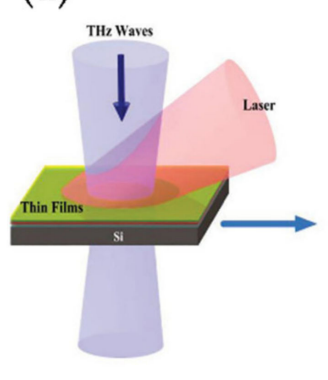

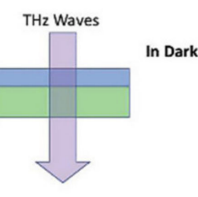

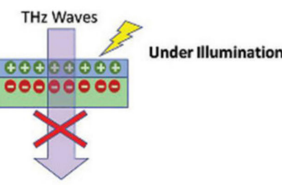

(b)

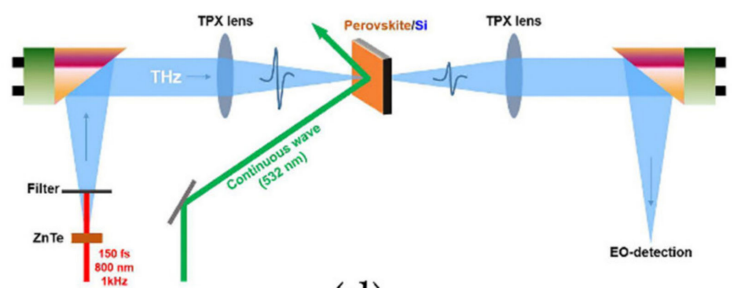

(d)
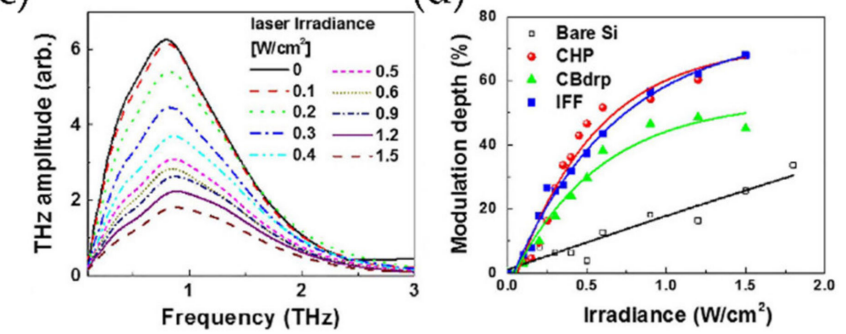

Figure 8. (a) Operation mechanism of the all-optical THz modulator under laser irradiation Reproduced with permission from [21]; published by Wiley, 2020. (b) Schematic of the THz all-optical modulation measurement; (c) THz transmittance under different laser irradiance and (d) the corresponding modulation depth (MD). Reproduced with permission from [22]; published by Springer Nature, 2016.

Table 3. Device parameters for the LHP-based THz modulators.

\begin{tabular}{ccccc}
\hline Materials & Pump (nm) & MD & Saturation Intensity & Range (THz) \\
\hline $\mathrm{MAPbI}_{3} /$ silicon [23] & 450 & $\approx 100 \%$ & $0.42 \mathrm{~W} / \mathrm{cm}^{2}$ & $0.2-2.6$ \\
$\mathrm{MAPbI}_{3} /$ silicon [22] & 532 & $68 \%$ & $0.5 \mathrm{~W} / \mathrm{cm}^{2}$ & $0.2-2$ \\
$\mathrm{MAPbBr}_{3} /$ silicon [113] & 450 & $80 \%$ & $3 \mathrm{~W} / \mathrm{cm}^{2}$ & $0.2-2.6$ \\
$\mathrm{PCBM}^{*} / \mathrm{MAPI}_{3} /$ PEDOT:PSS/silicon [21] & 980 & $99.5 \%$ & $2.18 \mathrm{~W} / \mathrm{cm}^{2}$ & $0.3-0.5$ \\
$\mathrm{CSPBr}_{3} /$ silicon [114] & 450 & $45.5 \%$ & $2 \mathrm{~W} / \mathrm{cm}^{2}$ & $0.23-0.35$ \\
\hline
\end{tabular}

PCBM is short for [6,6]-phenyl-C61-butyric acid methyl ester.

These days, both modulators with planar structure and metamaterials have been reported, as shown in Figure 9. Zhang et al. [23] reported the use of $\mathrm{MAPbI}_{3} /$ Silicon structure to modulate $\mathrm{THz}$ wave in $0.2-2.6 \mathrm{THz}$ range, by using a $450 \mathrm{~nm} \mathrm{cw}$ laser as the pump light. The $\mathrm{MAPbI}_{3}$ thin film was conveniently spin-coated onto a silicon substrate to form heterostructures. The silicon layer could strongly absorb the $450 \mathrm{~nm}$ laser and generate charge carriers which then drift to the LHP-silicon interface, resulting in an enhanced carrier density. It is found that the device transmittance and reflection could be efficiently modulated, and a modulation depth (MD) of nearly $100 \%$ could be achieved. As compared to silicon-based modulator, the MD is greatly enhanced in the hybrid device and the saturation intensity of the device $\left(\sim 0.42 \mathrm{~W} / \mathrm{cm}^{2}\right)$ is much lower than that in graphene/silicon based devices [115]. Lee et al. reported the optical modulation of an intenser $\mathrm{THz}$ wave using $532 \mathrm{~nm}$ laser [22]. Since the absorption at $532 \mathrm{~nm}$ for silicon is considerably lower than that at $450 \mathrm{~nm}$, the $\mathrm{THz}$ absorption enhancement at $532 \mathrm{~nm}$ is less. At a $1.5 \mathrm{~W} / \mathrm{cm}^{2}$ laser illumination, a reduced $\mathrm{MD}(68 \%)$ has been achieved. Lai et al. demonstrated a silicon-PEDOT:PSS-LHP THz wave modulator driven by a $980 \mathrm{~nm}$ continuous wave $(\mathrm{cw})$ laser [21], in contrast to previous reports using visible wavelength In order to obtain an even larger MD, the authors introduced both PCBM and PEDOT:PSS layers to further elongate the carrier recombination time. At a moderate NIR intensity of $2.18 \mathrm{~W} / \mathrm{cm}^{2}$, a MD of $-45 \mathrm{~dB}$ is achieved. 

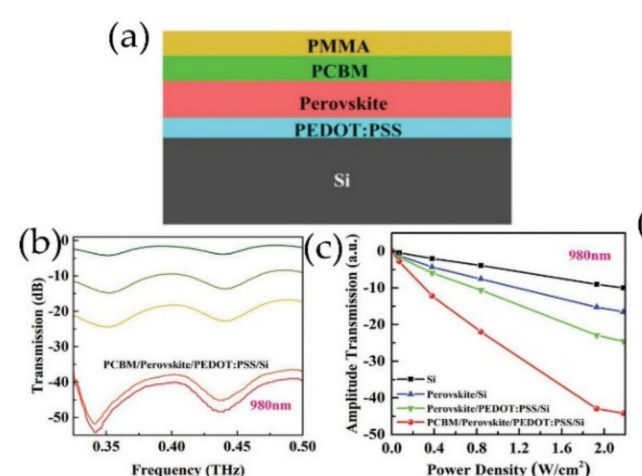

(e)

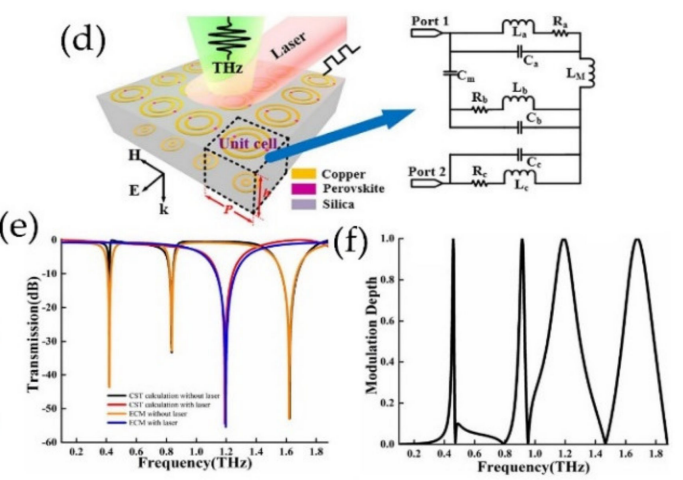

Figure 9. Different types of LHP THz modulators and their performances. (a). Lateral schematic illustration of the Si/PEDOT:PSS/LHP THz modulator. (b). The THz transmission of the hybrid modulator and (c). modulation depth (MD) comparison at $0.33 \mathrm{THz}$ for different structure. Reproduced with permission from [21]; published by Wiley, 2020. (d). A metamaterial/LHP THz modulator, with the equivalent circuit model of the unit cell shown on the right. (e). THz transmittance with and without laser irradiation; (f). the MD of the device. Reprinted from [116]. Copyright 2019, with permission from Elsevier.

In addition to the 3D LHP films, low-dimensional LHP has also been used in THz modulators. Li et al. reported a $\mathrm{CsPbBr}_{3} \mathrm{QDs} /$ silicon hybrid $\mathrm{THz}$ modulator, which operated in $0.23-0.35 \mathrm{THz}$ and was driven by a $450 \mathrm{~nm}$ laser [114]. Under $2 \mathrm{~W} / \mathrm{cm}^{2}$ pump light, a $45.5 \% \mathrm{MD}$ and $2.5 \mathrm{MHz}$ modulation frequency is achieved. Although the $\mathrm{MD}$ is less than that for the $\mathrm{MAPbI}_{3}$ / silicon device, $\mathrm{CsPbBr}_{3}$ QDs degrades in a slower rate than $\mathrm{MAPbI}_{3}$ and possibly leads to a longer lifespan. To achieve a multiband amplitude modulation, Wang et al. theoretically proposed a LHP QDs/metamaterial $\mathrm{THz}$ modulator [116]. The metamaterial unit was composed of a split-ring resonator (SRR) on the top and concentric double rings on the bottom. The LHP QDs were deliberately filled in the split gap of the SRR. With the presence of the split-ring, three resonant frequencies existed, leading to very low transmission (nearly goes to zero) at these frequencies. When the pump light was on, however, the conductivity of the LHP varied, and the split-ring changed into a metallic one. This consequently results in the alteration of resonant states and $\mathrm{THz}$ transmission modulation (at $0.42 \mathrm{THz}, 0.83 \mathrm{THz}, 1.18 \mathrm{THz}$, and $1.62 \mathrm{THz}$ ). The modulation speed was estimated to be larger than $3 \mathrm{MHz}$.

\section{The Fabrication of the LHP Based Devices}

\subsection{Massive Integration of LHP Devices}

It is highly desired that massive fabrication of the integrated LHP-based devices could be realized with low cost. To achieve this goal, an effective lithographic approach that can define desired LHP patterns is urgently needed. In general, there are several key points for the effective lithographic approach. Firstly, it is important to cover the LHP with a layer of resist on which the structures with micrometer or submicrometer resolution can be patterned. Secondly, the LHP film, unprotected by patterned resist mask, should be completely removed. Thirdly, the final residual resist mask should also be removed from the LHP film, while the removal will not introduce considerable pollution or damage to the device. Lyashenko et al. reported a method to develop $\mathrm{MAPbI}_{3}$ film demonstrating micrometer-resolution patterns, using photolithography followed by $\mathrm{SF}_{6}$ etching [117]. In this approach, desired pattern was defined in photoresist (OSCoR1000 negative photoresist) on top of $\mathrm{MAPbI}_{3}$ film. $\mathrm{SF}_{6}$ plasma reactive ion etching (RIE) was subsequently used to facilitate pattern transfer. This micrometer-resolution patterning technique of $\mathrm{MAPbI}_{3}$ was shown to be effective in reducing signal crosstalk between neighboring photodetector pixels. However, the RIE process only modifies the exposed film chemically (converting the material into $\mathrm{PbF}_{2}$ ) but does not remove the LHP layer completely as desired. Additionally, the resolution is limited to micrometer level due to diffraction limit. Zhang et al. explored 
a different fabrication process for LHP devices [118]. In this approach, micro- or nanosized structures were patterned in poly (methyl methacrylate) (PMMA) resist with electron beam lithography (EBL). Inductively coupled plasma (ICP) etching was used to transfer the structures to $\mathrm{MAPbBr}_{3}$ film. Compared with the conventional LHP photodetector, the advantage of EBL-fabricated photodetector was clearly shown by authors. Even though this method can potentially generate high-resolution features ( nanosize), it is based on EBL process and is thus limited in terms of cost and speed. In addition, the undesired LHP layer could not be removed completely by ICP process. A different approach of pattern transfer, utilizing lift-off instead of etching, was reported by Daus et al. The substrate (polyimide $/ \mathrm{SiN}_{\mathrm{x}} / \mathrm{Al}_{2} \mathrm{O}_{3}$ and polyimide $/ \mathrm{SiN}_{\mathrm{x}} / \mathrm{Al}_{2} \mathrm{O}_{3} / \mathrm{Au}$ ) was initially covered by a double-layer of PMMA resist with different molecular weights in this approach [119]. Subsequently, the resist layer was exposed by deep ultraviolet (DUV) lithography. Then $\mathrm{MAPbI}_{3}$ film was deposited directly on the substrate by thermal coevaporation where $\mathrm{CH}_{3} \mathrm{NH}_{3} \mathrm{I}$ (MAI) and $\mathrm{PbI}_{2}$ were in use as target materials. Finally, the PMMA was dissolved in chlorobenzene, thereby lifting off the undesired $\mathrm{MAPbI}_{3}$. The PMMA lift-off procedure developed the first demonstration of $\mathrm{MAPbI}_{3}$ as a gate dielectric revealing extraordinary channel control due to its giant dielectric constant. However, this technique that can realize complete removal of undesired layer requires the evaporation of LHP film, which is not compatible with the spin-coating film preparation method used by above methods. The spin-coating preparation of film is simple and inexpensive, so it can render LHP attractive for device integrated systems. Taking the above-mentioned reports into consideration, a complete, high-resolution, and scalable lithographic approach for patterning metal-halide LHP film is rare to some extent.

In a report by Pourdavoud et al., the nanostructures were prepared with thermal nanoimprint lithography (NIL) directly in $\mathrm{MAPbI}_{3}$ film at temperature as low as $100{ }^{\circ} \mathrm{C}$ [120]. The $\mathrm{MAPbI}_{3}$ layer used in this study was prepared by spin coating from a lead acetate $\left(\mathrm{Pb}(\mathrm{OAc})_{2}\right)$ and MAI solution in dimethylformamide (DMF). The stamp used in direct-NIL process consisted of a $500 \mu \mathrm{m}$ thick Si backplane and a $20 \mu \mathrm{m}$ thick patterned top layer generated from Ormostamp (Microresist, Berlin, Germany). By adopting this direct-NIL approach, 2D photonic crystals with a periodicity of $450 \mathrm{~nm}$ and a diameter of the pillars of $230 \mathrm{~nm}$ were prepared. The photonic devices were demonstrated to afford lasing with a very low threshold of $3.8 \mu \mathrm{J} \mathrm{cm}{ }^{-2}$ at room temperature, which indicated that the $\mathrm{MAPbI}_{3}$ layer remained excellent quality after nanoimprint. Although the direct-NIL approach can easily generate submicrometer structures of metal-halide LHP, it is practically impossible to remove material completely in arbitrary geometries as described due to the nature of its operation. Fortunately, this insight from the direct-NIL process will provide an avenue to pattern these LHP for the applications of functional devices enabled by metal-halide. Based on the direct-NIL approach, Bar-on et al. investigated a method to pattern $\mathrm{MAPbI}_{3}$ film using nanoimprint lithography (NIL) followed by ion beam milling (IBM) [121], for which the general lithography procedure is shown in Figure 10. In this approach, NIL step was utilized to imprint patterns in the resist (mr-I T85-0.3) on top of $\mathrm{MAPbI}_{3}$ film while the IBM process (Argon ion beam) completely removed the unprotected LHP layer. Finally, short sonication in toluene was applied to remove the residual imprint resist. Further, by combining this NIL-IBM process with above direct-NIL process, the authors realized LHP-based micro lasers. In this new and comprehensive approach, elements geometry and position were defined using NIL-IBM process and subsequently the distributed reflector was patterned into the structure using direct-NIL process. Being simple, fast, inexpensive, and scalable, the demonstrated approach points a highly attractive lithography scheme for LHP and offers an important tool towards integrated LHP devices. The achieved nanofeatures are shown in Figure 11. 


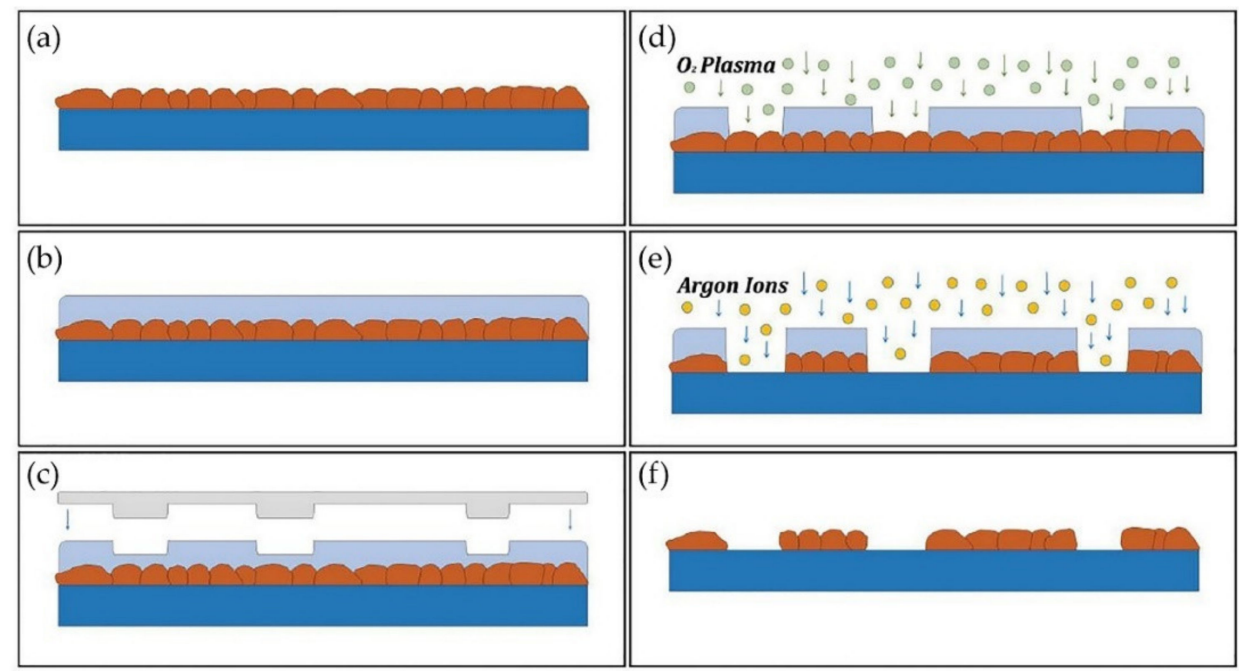

Figure 10. A lithography scheme for the LHP. (a) Preparation of thin LHP films; (b) Imprint resist spin coating. (c) Pattern imprinting into the resist. (d) Removal of the residual resist to reach the LHP film. (e) Argon ion beam milling of the unprotected LHP areas. (f) Removal of the residual imprint resist. Reproduced with permission from [121]; published by Wiley, 2018.
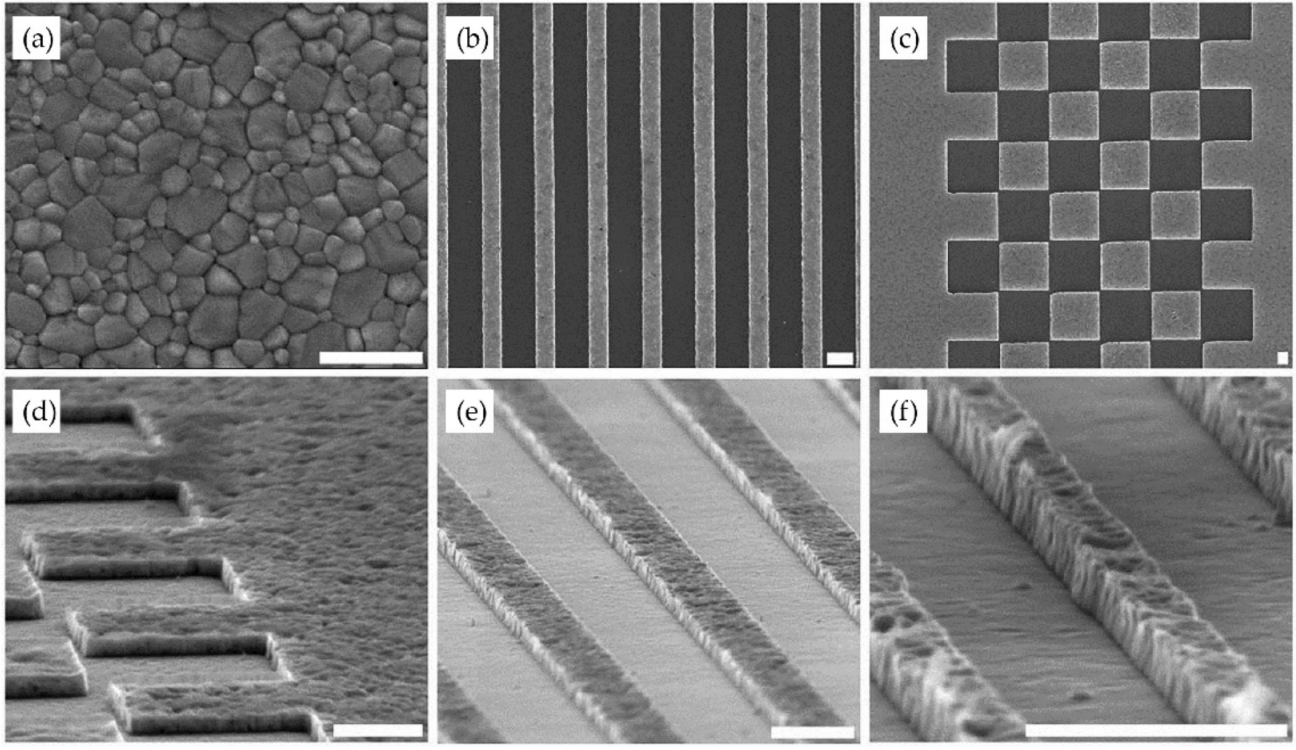

Figure 11. SEM images of various LHP structures after a complete lithography process. (a) Unetched area, top view; (b) Lines, top view; (c) Squares, top view; (d) Squares and unetched film, tilted view; (e) Lines with width $<1 \mu \mathrm{m}$; (f) $250 \mathrm{~nm}$ wide lines. The scale bars in the Figure correspond to $1 \mu \mathrm{m}$. Reproduced with permission from [121]; published by Wiley, 2018.

\subsection{Device Protection}

Due to the tendency to degradation in LHP, device protection is often necessary for most of the LHP devices. It has been shown that device protection such as encapsulation and introduction of barrier layers is very effective when compared to the unprotected devices. For instance, in the LHP/ $\mathrm{MoS}_{2}$ photodetector [95], both octadecyltrichlorosilane (OTS) and PMMA were used to encapsulate the device which could provide a good optical transparency simultaneously. The device without encapsulation deteriorated in photoresponsivity and detectivity after $48 \mathrm{~h}$; the encapsulated device, on the other hand, deteriorated less than $30 \%$ after $200 \mathrm{~h}$. The degradation due to the exposure of moisture and oxygen could be considerably reduced by the protections above. On the other hand, the light-induced degradation forms the major bottleneck limiting the practical usage of 
LHP devices for long working lifespan, as it could be avoided by the protections mentioned above. It is expected that a better understanding on the mechanism of light-induced degradation could benefit the solving of this problem.

\section{Summary and Outlook}

In summary, the LHPs have been utilized in various functional devices such as lasers, photodetectors, modulators, and so on. The utilization of the material is due to its superior opto-electronic properties, as well as its low-cost fabrication and easiness to be combined with other materials. By now, LHP have been combined with semiconductors, metals, as well as polymers. By a careful material selection and device design, the device performance could be further enhanced.

Due to the uniqueness of LHP, how to improve the working performance and lifespan are the two essential points concerned by researchers in the community. Certainly, the property of the corresponding LHP in use is the dominating factor. The interactions between particles including carriers, photons, and phonons, etc., could affect the working performance from one way or another. For instance, the lasing threshold in the LHP-lasers has been shown to be affected significantly when the LHP's crystalline quality or film morphology varies: when the number of scattering centers or grain boundaries inside LHP is reduced, a lower threshold is generally expected. A reduced trap density, on the other hand, could possibly lead to the ultrafast response in photodetectors. With the development in single-crystal LHP growth, LHPs with improved crystalline qualities as well as enhanced performance in the devices could be expected. Moreover, a better crystalline quality also tends to result in higher-level stability, which could be possibly ascribed by the higher thermal conductivity and thus faster heat dissipation. In some of the previous reports, LHPs with higher stability have been used to elongate the device lifespan but often introduced a trade-off of a deterioration in device performances at the same time (for instance, a narrower working bandwidth when switching from $\mathrm{MAPbI}_{3}$ to $\mathrm{CsPbI}_{3}$ in photodetectors). An improved crystal quality could provide the researchers with a higher degree of freedom when selecting the proper LHP materials, resulting in more robust devices as well.

Currently, it is beneficial to realize that there is still much to be studied regarding the LHP's optical and electrical properties. It is necessary to not only characterize the important parameters but also to obtain an in-depth understanding on light-matter interactions inside LHP. The dynamics of photogenerated carriers, the behavior of traps, and so forth, could affect the device performance in one way or another. A deeper understanding regarding the perovskites' optical and electrical properties, could aid people in finding out the optimized working conditions to the LHP-devices. Moreover, since light is a necessity for most of the functional devices and leads to decomposition in LHP, efforts regarding the light-induced degradation mechanism will also be beneficial. With a better understanding of how the crystalline and electronic structure changes when exposed to light illumination, people will be able to determine the proper illumination condition for each type of functional devices and estimate the performance degradation with more certainty. The knowledge of light-induced degradation mechanism will also contribute to synthesis of new LHPs with improved stability.

The design of device configuration is also a significant factor leading to development in LHP devices. Generally, the improvement is achieved by increasing the optical length (through cavity design) and/or enhancing the optical confinement in LHP (through design of material spatial layout or introduction of plasmonic effects). However, caution is needed when the optical field distribution and the degree of optical confinement is to be steered, since the degradation in LHP has been found to accelerate in light illumination with higher power density. In addition to concerns regarding device performance and lifespan, the device configuration should also be inspected carefully from the aspects of fabrication feasibility, such as the cost, complexity, and the compatibility with the existing fabrication flows [122]. With the development in LHP material growth, as well as in scalable fabricating 
techniques, massive fabrication of integrated LHP-based functional devices with improved performance and stability could be expected.

Author Contributions: Conceptualization, H.L., L.Z.; Investigation, H.L., H.Z. and X.X.; writingoriginal draft, H.L., H.Z. and X.X.; writing-review and editing, H.L., H.Z., X.X. and L.Z. All authors have read and agreed to the published version of the manuscript.

Funding: This research was funded by National Key R\&D Program of China under grant 2019YFB2203902 and National Natural Science Foundation of China (NSFC) under grant 62005192.

Institutional Review Board Statement: Not applicable.

Informed Consent Statement: Not applicable.

Data Availability Statement: No new data were created or analyzed in this study. Data sharing is not applicable to this article.

Acknowledgments: The authors acknowledge the support by the Advanced Integrated Optoelectronics Facility at Tianjin University and the financial support by National Key R\&D Program of China under grant 2019YFB2203902.

Conflicts of Interest: The authors declare no conflict of interest.

\section{References}

1. Fu, Q.; Tang, X.; Huang, B.; Hu, T.; Tan, L.; Chen, L.; Chen, Y. Recent Progress on the Long-Term Stability of Perovskite Solar Cells. Adv. Sci. 2018, 5, 1700387. [CrossRef] [PubMed]

2. Cha, H.; Bae, S.; Lee, M.; Jeon, H. Two-dimensional photonic crystal bandedge laser with hybrid perovskite thin film for optical gain. Appl. Phys. Lett. 2016, 108, 181104. [CrossRef]

3. Noel, N.K.; Stranks, S.D.; Abate, A.; Wehrenfennig, C.; Guarnera, S.; Haghighirad, A.-A.; Sadhanala, A.; Eperon, G.E.; Pathak, S.K.; Johnston, M.B.; et al. Lead-free organic-inorganic tin halide perovskites for photovoltaic applications. Energy Environ. Sci. 2014, 7, 3061-3068. [CrossRef]

4. Hoefler, S.F.; Trimmel, G.; Rath, T. Progress on lead-free metal halide perovskites for photovoltaic applications: A review. Monatshefte Chem. Chem. Mon. 2017, 148, 795-826. [CrossRef]

5. Huang, C.-Y.; Zou, C.; Mao, C.; Corp, K.L.; Yao, Y.-C.; Lee, Y.-J.; Schlenker, C.W.; Jen, A.K.Y.; Lin, L.Y. CsPbBr3 Perovskite Quantum Dot Vertical Cavity Lasers with Low Threshold and High Stability. Acs Photonics 2017, 4, 2281-2289. [CrossRef]

6. Jia, Y.; Kerner, R.A.; Grede, A.J.; Brigeman, A.N.; Rand, B.P.; Giebink, N.C. Diode-Pumped Organo-Lead Halide Perovskite Lasing in a Metal-Clad Distributed Feedback Resonator. Nano Lett. 2016, 16, 4624-4629. [CrossRef]

7. Chen, S.; Roh, K.; Lee, J.; Chong, W.K.; Lu, Y.; Mathews, N.; Sum, T.C.; Nurmikko, A. A Photonic Crystal Laser from Solution Based Organo-Lead Iodide Perovskite Thin Films. Acs Nano 2016, 10, 3959-3967. [CrossRef]

8. Cha, H.; Bae, S.; Jung, H.; Ko, M.J.; Jeon, H. Single-Mode Distributed Feedback Laser Operation in Solution-Processed Halide Perovskite Alloy System. Adv. Opt. Mater. 2017, 5, 1700545. [CrossRef]

9. Liu, J.-Q.; Gao, Y.; Wu, G.-A.; Tong, X.-W.; Xie, C.; Luo, L.-B.; Liang, L.; Wu, Y.-C. Silicon/Perovskite Core-Shell Heterojunctions with Light-Trapping Effect for Sensitive Self-Driven Near-Infrared Photodetectors. ACS Appl. Mater. Interfaces 2018, 10, 27850-27857. [CrossRef]

10. Mączka, M.; Ptak, M.; Gagor, A.; Stefańska, D.; Zaręba, J.K.; Sieradzki, A. Methylhydrazinium Lead Bromide: Noncentrosymmetric Three-Dimensional Perovskite with Exceptionally Large Framework Distortion and Green Photoluminescence. Chem. Mater. 2020, 32, 1667-1673. [CrossRef]

11. Mączka, M.; Gagor, A.; Zaręba, J.K.; Stefanska, D.; Drozd, M.; Balciunas, S.; Šimènas, M.; Banys, J.; Sieradzki, A. ThreeDimensional Perovskite Methylhydrazinium Lead Chloride with Two Polar Phases and Unusual Second-Harmonic Generation Bistability above Room Temperature. Chem. Mater. 2020, 32, 4072-4082. [CrossRef]

12. Lou, H.; Ye, Z.; He, H. Recent advances in photo-stability of lead halide perovskites. Acta Phys. Sin. 2019, 68, 157102-1.

13. Ono, L.K.; Qi, Y.; Liu, S. Progress toward Stable Lead Halide Perovskite Solar Cells. Joule 2018, 2, 1961-1990. [CrossRef]

14. Chen, S.; Zhang, C.; Lee, J.; Han, J.; Nurmikko, A. High-Q, Low-Threshold Monolithic Perovskite Thin-Film Vertical-Cavity Lasers. Adv. Mater. 2017, 29, 1604781. [CrossRef] [PubMed]

15. Liu, X.K.; Xu, W.; Bai, S.; Jin, Y.; Gao, F. Metal halide perovskites for light-emitting diodes. Nat. Mater. 2020, 20, 10-21. [CrossRef] [PubMed]

16. Lin, K.; Xing, J.; Quan, L.N.; de Arquer, F.P.G.; Gong, X.; Lu, J.; Xie, L.; Zhao, W.; Zhang, D.; Yan, C.; et al. Perovskite light-emitting diodes with external quantum efficiency exceeding 20 per cent. Nature 2018, 562, 245-248. [CrossRef]

17. Zhao, B.; Bai, S.; Kim, V.; Lamboll, R.; Shivanna, R.; Auras, F.; Richter, J.M.; Yang, L.; Dai, L.; Alsari, M.; et al. High-efficiency perovskite-polymer bulk heterostructure light-emitting diodes. Nat. Photon. 2018, 12, 783-789. [CrossRef]

18. Alwadai, N.; Haque, M.A.; Mitra, S.; Flemban, T.; Pak, Y.; Wu, T.; Roqan, I. High-Performance Ultraviolet-to-Infrared Broadband Perovskite Photodetectors Achieved via Inter-/Intraband Transitions. Acs Appl. Mater. Interfaces 2017, 9, 37832-37838. [CrossRef] 
19. Song, X.; Liu, X.; Yu, D.; Huo, C.; Ji, J.; Li, X.; Zhang, S.; Zou, Y.; Zhu, G.; Wang, Y.; et al. Boosting Two-Dimensional MoS $2 /$ CsPbBr $_{3}$ Photodetectors via Enhanced Light Absorbance and Interfacial Carrier Separation. Acs Appl. Mater. Interfaces 2018, 10, 2801-2809. [CrossRef]

20. Zou, X.; Li, Y.; Tang, G.; You, P.; Yan, F. Schottky Barrier-Controlled Black Phosphorus/Perovskite Phototransistors with Ultrahigh Sensitivity and Fast Response. Small 2019, 15, e1901004. [CrossRef]

21. Lai, W.; Ge, C.; Yuan, H.; Dong, Q.; Yang, D.; Fang, Y. NIR Light Driven Terahertz Wave Modulator with a Large Modulation Depth Based on a Silicon-PEDOT:PSS-Perovskite Hybrid System. Adv. Mater. Technol. 2020, 5, 1901090. [CrossRef]

22. Lee, K.-S.; Kang, R.; Son, B.; Kim, D.-Y.; Yu, N.E.; Ko, D.-K. All-optical THz wave switching based on $\mathrm{CH}_{3} \mathrm{NH}_{3} \mathrm{PbI}_{3}$ perovskites Sci. Rep. 2016, 6, 37912. [CrossRef] [PubMed]

23. Zhang, B.; Lv, L.; He, T.; Chen, T.; Zang, M.; Zhong, L.; Wang, X.; Shen, J.; Hou, Y. Active terahertz device based on optically controlled organometal halide perovskite. Appl. Phys. Lett. 2015, 107, 93301. [CrossRef]

24. Walters, G.; Sutherland, B.R.; Hoogland, S.; Shi, D.; Comin, R.; Sellan, D.P.; Bakr, O.M.; Sargent, E.H. Two-Photon Absorption in Organometallic Bromide Perovskites. ACS Nano 2015, 9, 9340-9346. [CrossRef]

25. Xu, Y.; Chen, Q.; Zhang, C.; Wang, R.; Wu, H.; Zhang, X.; Xing, G.; Yu, W.W.; Wang, X.; Zhang, Y.; et al. Two-Photon-Pumped Perovskite Semiconductor Nanocrystal Lasers. J. Am. Chem. Soc. 2016, 138, 3761-3768. [CrossRef]

26. Wang, Y.; Li, X.; Zhao, X.; Xiao, L.; Zeng, H.; Sun, H. Nonlinear Absorption and Low-Threshold Multiphoton Pumped Stimulated Emission from All-Inorganic Perovskite Nanocrystals. Nano Lett. 2016, 16, 448-453. [CrossRef]

27. Chen, W.; Bhaumik, S.; Veldhuis, S.A.; Xing, G.; Xu, Q.; Grätzel, M.; Mhaisalkar, S.; Mathews, N.; Sum, T.C. Giant five-photon absorption from multidimensional core-shell halide perovskite colloidal nanocrystals. Nat. Commun. 2017, 8, 15198. [CrossRef]

28. Kitazawa, N.; Watanabe, Y.; Nakamura, Y. Optical properties of $\mathrm{CH}_{3} \mathrm{NH}_{3} \mathrm{PbX}_{3}(\mathrm{X}=$ halogen) and their mixed-halide crystals. J. Mater. Sci. 2002, 37, 3585-3587. [CrossRef]

29. Sutherland, B.R.; Sargent, E.H. Perovskite photonic sources. Nat. Photon. 2016, 10, 295-302. [CrossRef]

30. Yin, W.J.; Shi, T.T.; Yan, Y.F. Unique Properties of Halide Perovskites as Possible Origins of the Superior Solar Cell Performance. Adv. Mater. 2014, 26, 4653-4658. [CrossRef]

31. Deschler, F.; Price, M.; Pathak, S.; Klintberg, L.E.; Jarausch, D.-D.; Higler, R.; Hüttner, S.; Leijtens, T.; Stranks, S.D.; Snaith, H.J.; et al. High Photoluminescence Efficiency and Optically Pumped Lasing in Solution-Processed Mixed Halide Perovskite Semiconductors. J. Phys. Chem. Lett. 2014, 5, 1421-1426. [CrossRef] [PubMed]

32. Sutherland, B.R.; Hoogland, S.; Adachi, M.M.; Kanjanaboos, P.; Wong, C.T.O.; McDowell, J.J.; Xu, J.; Voznyy, O.; Ning, Z.; Houtepen, A.J.; et al. Perovskite Thin Films via Atomic Layer Deposition. Adv. Mater. 2015, 27, 53-58. [CrossRef] [PubMed]

33. Protesescu, L.; Yakunin, S.; Bodnarchuk, M.I.; Krieg, F.; Caputo, R.; Hendon, C.H.; Yang, R.X.; Walsh, A.; Kovalenko, M.V. Nanocrystals of Cesium Lead Halide Perovskites $\left(\mathrm{CsPbX}_{3}, \mathrm{X}=\mathrm{Cl}, \mathrm{Br}\right.$, and I): Novel Optoelectronic Materials Showing Bright Emission with Wide Color Gamut. Nano Lett. 2015, 15, 3692-3696. [CrossRef] [PubMed]

34. Milot, R.L.; Eperon, G.E.; Snaith, H.J.; Johnston, M.B.; Herz, L.M. Temperature-Dependent Charge-Carrier Dynamics in CH3NH3PbI3 Perovskite Thin Films. Adv. Funct. Mater. 2015, 25, 6218-6227. [CrossRef]

35. Herz, L.M. Charge-Carrier Mobilities in Metal Halide Perovskites: Fundamental Mechanisms and Limits. ACS Energy Lett. 2017, 2, 1539-1548. [CrossRef]

36. Makarov, S.; Furasova, A.; Tiguntseva, E.; Hemmetter, A.; Berestennikov, A.; Pushkarev, A.; Zakhidov, A.; Kivshar, Y. HalidePerovskite Resonant Nanophotonics. Adv. Opt. Mater. 2019, 7, 1800784. [CrossRef]

37. Zhang, Y.; Lim, C.-K.; Dai, Z.; Yu, G.; Haus, J.W.; Zhang, H.; Prasad, P.N. Photonics and optoelectronics using nano-structured hybrid perovskite media and their optical cavities. Phys. Rep. 2019, 795, 1-51. [CrossRef]

38. Valverde-Chávez, D.A.; Ponseca, C.S.; Stoumpos, C.C.; Yartsev, A.; Kanatzidis, M.G.; Sundström, V.; Cooke, D.G. Intrinsic femtosecond charge generation dynamics in single crystal $\mathrm{CH}_{3} \mathrm{NH}_{3} \mathrm{PbI}_{3}$. Energy Environ. Sci. 2015, 8, 3700-3707. [CrossRef]

39. Dong, Q.; Fang, Y.; Shao, Y.; Mulligan, P.; Qiu, J.; Cao, L.; Huang, J. Electron-hole diffusion lengths $>175 \mu \mathrm{m}$ in solution-grown $\mathrm{CH}_{3} \mathrm{NH}_{3} \mathrm{PbI}_{3}$ single crystals. Science 2015, 347, 967-970. [CrossRef]

40. Stranks, S.D.; Eperon, G.E.; Grancini, G.; Menelaou, C.; Alcocer, M.J.P.; Leijtens, T.; Herz, L.M.; Petrozza, A.; Snaith, H.J. ElectronHole Diffusion Lengths Exceeding 1 Micrometer in an Organometal Trihalide Perovskite Absorber. Science 2013, 342, 341-344. [CrossRef]

41. Xing, G.; Mathews, N.; Sun, S.; Lim, S.S.; Lam, Y.M.; Grätzel, M.; Mhaisalkar, S.; Sum, T.C. Long-Range Balanced Electron- and Hole-Transport Lengths in Organic-Inorganic $\mathrm{CH}_{3} \mathrm{NH}_{3} \mathrm{PbI}_{3}$. Science 2013, 342, 344-347. [CrossRef] [PubMed]

42. Eperon, G.E.; Stranks, S.D.; Menelaou, C.; Johnston, M.B.; Herz, L.M.; Snaith, H.J. Formamidinium lead trihalide: A broadly tunable perovskite for efficient planar heterojunction solar cells. Energy Environ. Sci. 2014, 7, 982-988. [CrossRef]

43. Bai, S.; Wu, Z.; Wu, X.; Jin, Y.; Zhao, N.; Chen, Z.; Mei, Q.; Wang, X.; Ye, Z.; Song, T.; et al. High-performance planar heterojunction perovskite solar cells: Preserving long charge carrier diffusion lengths and interfacial engineering. Nano Res. 2014, 7, 1749-1758. [CrossRef]

44. Deng, Y.; Peng, E.; Shao, Y.; Xiao, Z.; Dong, Q.; Huang, J. Scalable fabrication of efficient organolead trihalide perovskite solar cells with doctor-bladed active layers. Energy Environ. Sci. 2015, 8, 1544-1550. [CrossRef]

45. Fang, Y.; Dong, Q.; Shao, Y.; Yuan, Y.; Huang, J. Highly narrowband perovskite single-crystal photodetectors enabled by surface-charge recombination. Nat. Photon. 2015, 9, 679-686. [CrossRef] 
46. Han, Y.; Meyer, S.; Dkhissi, Y.; Weber, K.; Pringle, J.M.; Bach, U.; Spiccia, L.; Cheng, Y.B. Degradation observations of encapsulated planar $\mathrm{CH}_{3} \mathrm{NH}_{3} \mathrm{PbI}_{3}$ perovskite solar cells at high temperatures and humidity. J. Mater. Chem. A 2015, 3, 8139-8147. [CrossRef]

47. Bryant, D.; Aristidou, N.; Pont, S.; Sanchez-Molina, I.; Chotchunangatchaval, T.; Wheeler, S.; Durrant, J.R.; Haque, S.A. Light and oxygen induced degradation limits the operational stability of methylammonium lead triiodide perovskite solar cells. Energy Environ. Sci. 2016, 9, 1655-1660. [CrossRef]

48. Dualeh, A.; Gao, P.; Seok, S.I.; Nazeeruddin, M.K.; Graetzel, M. Thermal Behavior of Methylammonium Lead-Trihalide Perovskite Photovoltaic Light Harvesters. Chem. Mater. 2014, 26, 6160-6164. [CrossRef]

49. Noh, J.H.; Im, S.H.; Heo, J.H.; Mandal, T.N.; Seok, S.I. Chemical Management for Colorful, Efficient, and Stable Inorganic-Organic Hybrid Nanostructured Solar Cells. Nano Lett. 2013, 13, 1764-1769. [CrossRef]

50. Lang, F.; Shargaieva, O.; Brus, V.V.; Neitzert, H.C.; Rappich, J.; Nickel, N.H. Influence of Radiation on the Properties and the Stability of Hybrid Perovskites. Adv. Mater. 2018, 30, 1702905. [CrossRef]

51. Conings, B.; Drijkoningen, J.; Gauquelin, N.; Babayigit, A.; D’Haen, J.; D’Olieslaeger, L.; Ethirajan, A.; Verbeeck, J.; Manca, J.; Mosconi, E.; et al. Intrinsic Thermal Instability of Methylammonium Lead Trihalide Perovskite. Adv. Energy Mater. 2015, 5, 1500477. [CrossRef]

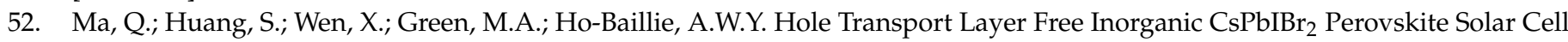
by Dual Source Thermal Evaporation. Adv. Energy Mater. 2016, 6, 1502202. [CrossRef]

53. Song, Z.N.; Abate, A.; Watthage, S.C.; Liyanage, G.K.; Phillips, A.B.; Steiner, U.; Graetzel, M.; Heben, M.J. Perovskite Solar Cell Stability in Humid Air: Partially Reversible Phase Transitions in the $\mathrm{PbI}_{2}-\mathrm{CH}_{3} \mathrm{NH}_{3} \mathrm{I}-\mathrm{H}_{2} \mathrm{O}$ System. Adv. Energy Mater. 2016, 6, 1600846. [CrossRef]

54. Jacobsson, T.J.; Tress, W.; Correa-Baena, J.P.; Edvinsson, T.; Hagfeldt, A. Room Temperature as a Goldilocks Environment for $\mathrm{CH}_{3} \mathrm{NH}_{3} \mathrm{PbI}_{3}$ Perovskite Solar Cells: The Importance of Temperature on Device Performance. J. Phys. Chem. C 2016, 120, 11382-11393. [CrossRef]

55. Wang, Y.; Gan, L.; Chen, J.; Yang, R.; Zhai, T. Achieving highly uniform two-dimensional PbI2 flakes for photodetectors via space confined physical vapor deposition. Sci. Bull. 2017, 62, 1654-1662. [CrossRef]

56. Zhao, C.; Chen, B.; Qiao, X.; Luan, L.; Lu, K.; Hu, B. Revealing Underlying Processes Involved in Light Soaking Effects and Hysteresis Phenomena in Perovskite Solar Cells. Adv. Energy Mater. 2015, 5, 1500279. [CrossRef]

57. Huang, F.; Jiang, L.; Pascoe, A.R.; Yan, Y.; Bach, U.; Spiccia, L.; Cheng, Y.-B. Fatigue behavior of planar $\mathrm{CH}_{3} \mathrm{NH}_{3} \mathrm{PbI}_{3}$ perovskite solar cells revealed by light on/off diurnal cycling. Nano Energy 2016, 27, 509-514. [CrossRef]

58. Bag, M.; Renna, L.A.; Adhikari, R.Y.; Karak, S.; Liu, F.; Lahti, P.M.; Russell, T.P.; Tuominen, M.T.; Venkataraman, D. Kinetics of Ion Transport in Perovskite Active Layers and Its Implications for Active Layer Stability. J. Am. Chem. Soc. 2015, 137, 13130-13137. [CrossRef]

59. Domanski, K.; Roose, B.; Matsui, T.; Saliba, M.; Turren-Cruz, S.-H.; Correa-Baena, J.-P.; Carmona, C.R.; Richardson, G.; Foster, J.M.; De Angelis, F.; et al. Migration of cations induces reversible performance losses over day/night cycling in perovskite solar cells. Energy Environ. Sci. 2017, 10, 604-613. [CrossRef]

60. Ha, S.T.; Liu, X.; Zhang, Q.; Giovanni, D.; Sum, T.C.; Xiong, Q. Synthesis of Organic-Inorganic Lead Halide Perovskite Nanoplatelets: Towards High-Performance Perovskite Solar Cells and Optoelectronic Devices. Adv. Opt. Mater. 2014, 2, 838-844. [CrossRef]

61. Park, B.W.; Jain, S.M.; Zhang, X.; Hagfeldt, A.; Boschloo, G.; Edvinsson, T. Resonance Raman and Excitation Energy Dependent Charge Transfer Mechanism in Halide-Substituted Hybrid Perovskite Solar Cells. ACS Nano 2015, 9, 2088-2101. [CrossRef] [PubMed]

62. Ledinský, M.; Löper, P.; Niesen, B.; Holovský, J.; Moon, S.-J.; Yum, J.-H.; De Wolf, S.; Fejfar, A.; Ballif, C. Raman Spectroscopy of Organic-Inorganic Halide Perovskites. J. Phys. Chem. Lett. 2015, 6, 401-406. [CrossRef] [PubMed]

63. Gottesman, R.; Gouda, L.; Kalanoor, B.S.; Haltzi, E.; Tirosh, S.; Rosh-Hodesh, E.; Tischler, Y.; Zaban, A.; Quarti, C.; Mosconi, E.; et al. Photoinduced Reversible Structural Transformations in Free-Standing $\mathrm{CH}_{3} \mathrm{NH}_{3} \mathrm{PbI}_{3}$ Perovskite Films. J. Phys. Chem. Lett. 2015, 6, 2332-2338. [CrossRef] [PubMed]

64. Chen, Q.; Liu, H.; Kim, H.-S.; Liu, Y.; Yang, M.; Yue, N.; Ren, G.; Zhu, K.; Liu, S.; Park, N.-G.; et al. Multiple-Stage Structure Transformation of Organic-Inorganic Hybrid Perovskite $\mathrm{CH}_{3} \mathrm{NH}_{3} \mathrm{PbI}_{3}$. Phys. Rev. X 2016, 6, 031042. [CrossRef]

65. Leijtens, T.; Eperon, G.E.; Pathak, S.; Abate, A.; Lee, M.M.; Snaith, H.J. Overcoming ultraviolet light instability of sensitized TiO 2 with meso-superstructured organometal tri-halide perovskite solar cells. Nat. Commun. 2013, 4, 2885. [CrossRef]

66. Niu, G.D.; Li, W.Z.; Meng, F.Q.; Wang, L.D.; Dong, H.P.; Qiu, Y. Study on the stability of $\mathrm{CH}_{3} \mathrm{NH}_{3} \mathrm{PbI}_{3}$ films and the effect of post-modification by aluminum oxide in all-solid-state hybrid solar cells. J. Mater. Chem. A 2014, 2, 705-710. [CrossRef]

67. Lee, S.-W.; Kim, S.; Bae, S.; Cho, K.; Chung, T.; Mundt, L.E.; Lee, S.; Park, S.; Park, H.; Schubert, M.C.; et al. UV Degradation and Recovery of Perovskite Solar Cells. Sci. Rep. 2016, 6, 38150. [CrossRef]

68. Bella, F.; Griffini, G.; Correa-Baena, J.P.; Saracco, G.; Gratzel, M.; Hagfeldt, A.; Turri, S.; Gerbaldi, C. Improving efficiency and stability of perovskite solar cells with photocurable fluoropolymers. Science 2016, 354, 203-206. [CrossRef]

69. Zhang, H.; Liang, C.; Zhao, Y.; Sun, M.; Liu, H.; Liang, J.; Li, D.; Zhang, F.; He, Z. Dynamic interface charge governing the current-voltage hysteresis in perovskite solar cells. Phys. Chem. Chem. Phys. 2015, 17, 9613-9618. [CrossRef]

70. Mosconi, E.; Meggiolaro, D.; Snaith, H.J.; Stranks, S.D.; De Angelis, F. Light-induced annihilation of Frenkel defects in organo-lead halide perovskites. Energy Environ. Sci. 2016, 9, 3180-3187. [CrossRef]

71. Cacovich, S.; Ciná, L.; Matteocci, F.; Divitini, G.; Midgley, P.A.; Di Carlo, A.; Ducati, C. Gold and iodine diffusion in large area perovskite solar cells under illumination. Nanoscale 2017, 9, 4700-4706. [CrossRef] [PubMed] 
72. Saliba, M.; Wood, S.M.; Patel, J.B.; Nayak, P.K.; Huang, J.; Alexander-Webber, J.A.; Wenger, B.; Stranks, S.D.; Hoerantner, M.T.; Wang, J.T.-W.; et al. Structured Organic-Inorganic Perovskite toward a Distributed Feedback Laser. Adv. Mater. 2016, 28, 923-929. [CrossRef] [PubMed]

73. Brenner, P.; Stulz, M.; Kapp, D.; Abzieher, T.; Paetzold, U.W.; Quintilla, A.; Howard, I.A.; Kalt, H.; Lemmer, U. Highly stable solution processed metal-halide perovskite lasers on nanoimprinted distributed feedback structures. Appl. Phys. Lett. 2016, 109, 141106. [CrossRef]

74. Whitworth, G.L.; Harwell, J.R.; Miller, D.N.; Hedley, G.J.; Zhang, W.; Snaith, H.J.; Turnbull, G.A.; Samuel, I.D.W. Nanoimprinted distributed feedback lasers of solution processed hybrid perovskites. Opt. Express 2016, 24, 23677-23684. [CrossRef]

75. Sun, S.; Xiao, S.; Song, Q. Distributed Feedback Laser Based on Single Crystal Perovskite. J. Phys. Conf. Ser. 2017, $844,012022$. [CrossRef]

76. Mathies, F.; Brenner, P.; Hernandez-Sosa, G.; Howard, I.A.; Paetzold, U.W.; Lemmer, U. Inkjet-printed perovskite distributed feedback lasers. Opt. Express 2018, 26, A144-A152. [CrossRef]

77. Wang, K.; Wang, S.; Xiao, S.; Song, Q. Recent Advances in Perovskite Micro- and Nanolasers. Adv. Opt. Mater. 2018, 6, 1800278. [CrossRef]

78. Stranks, S.D.; Wood, S.M.; Wojciechowski, K.; Deschler, F.; Saliba, M.; Khandelwal, H.; Patel, J.B.; Elston, S.J.; Herz, L.M.; Johnston, M.B.; et al. Enhanced Amplified Spontaneous Emission in Perovskites Using a Flexible Cholesteric Liquid Crystal Reflector. Nano Lett. 2015, 15, 4935-4941. [CrossRef]

79. Wang, Y.; Li, X.; Nalla, V.; Zeng, H.; Sun, H. Solution-Processed Low Threshold Vertical Cavity Surface Emitting Lasers from All-Inorganic Perovskite Nanocrystals. Adv. Func. Mater. 2017, 27, 1605088. [CrossRef]

80. Sutherland, B.R.; Hoogland, S.; Adachi, M.M.; Wong, C.T.O.; Sargent, E.H. Conformal Organohalide Perovskites Enable Lasing on Spherical Resonators. Acs Nano 2014, 8, 10947-10952. [CrossRef]

81. Zheng, Z.; Zhuge, F.; Wang, Y.; Zhang, J.; Gan, L.; Zhou, X.; Li, H.; Zhai, T. Decorating Perovskite Quantum Dots in TiO 2 Nanotubes Array for Broadband Response Photodetector. Adv. Funct. Mater. 2017, 27, 1703115. [CrossRef]

82. Su, R.; Diederichs, C.; Wang, J.; Liew, T.C.H.; Zhao, J.; Liu, S.; Xu, W.; Chen, Z.; Xiong, Q. Room-Temperature Polariton Lasing in All-Inorganic Perovskite Nanoplatelets. Nano Lett. 2017, 17, 3982-3988. [CrossRef] [PubMed]

83. Yu, H.; Ren, K.; Wu, Q.; Wang, J.; Lin, J.; Wang, Z.; Xu, J.; Oulton, R.F.; Qu, S.; Jin, P. Organic-inorganic perovskite plasmonic nanowire lasers with a low threshold and a good thermal stability. Nanoscale 2016, 8, 19536-19540. [CrossRef] [PubMed]

84. Wang, S.; Fang, J.; Zhang, C.; Sun, S.; Wang, K.; Xiao, S.; Song, Q. Maskless Fabrication of Aluminum Nanoparticles for Plasmonic Enhancement of Lead Halide Perovskite Lasers. Adv. Opt. Mater. 2017, 5, 1700529. [CrossRef]

85. Zhao, J.; Yan, Y.; Wei, C.; Zhang, W.; Gao, Z.; Zhao, Y.S. Switchable Single-Mode Perovskite Microlasers Modulated by Responsive Organic Microdisks. Nano Lett. 2018, 18, 1241-1245. [CrossRef] [PubMed]

86. Liu, X.; Niu, L.; Wu, C.; Cong, C.; Wang, H.; Zeng, Q.; He, H.; Fu, Q.; Fu, W.; Yu, T.; et al. Periodic Organic-Inorganic Halide Perovskite Microplatelet Arrays on Silicon Substrates for Room-Temperature Lasing. Adv. Sci. 2016, 3, 1600137. [CrossRef]

87. Wang, K.; Gu, Z.; Liu, S.; Sun, W.; Zhang, N.; Xiao, S.; Song, Q. High-Density and Uniform Lead Halide Perovskite Nanolaser Array on Silicon. J. Phys. Chem. Lett. 2016, 7, 2549-2555. [CrossRef]

88. Sun, S.; Zhang, C.; Wang, K.; Wang, S.; Xiao, S.; Song, Q. Lead Halide Perovskite Nanoribbon Based Uniform Nanolaser Array on Plasmonic Grating. Acs Photon. 2017, 4, 649-656. [CrossRef]

89. Qin, L.; Lv, L.; Ning, Y.; Li, C.; Lu, Q.; Zhu, L.; Hu, Y.; Lou, Z.; Teng, F.; Hou, Y. Enhanced amplified spontaneous emission from morphology-controlled organic-inorganic halide perovskite films. RSC Adv. 2015, 5, 103674-103679. [CrossRef]

90. Liu, F.; Dong, Q.; Wong, M.K.; Djurišić, A.B.; Ng, A.; Ren, Z.; Shen, Q.; Surya, C.; Chan, W.K.; Wang, J.; et al. Is Excess PbI 2 Beneficial for Perovskite Solar Cell Performance? Adv. Energy Mater. 2016, 6, 1502206. [CrossRef]

91. Zeng, L.-H.; Chen, Q.-M.; Zhang, Z.-X.; Wu, D.; Yuan, H.; Li, Y.-Y.; Qarony, W.; Lau, S.P.; Luo, L.-B.; Tsang, Y.H. Multilayered $\mathrm{PdSe}_{2}$ /Perovskite Schottky Junction for Fast, Self-Powered, Polarization-Sensitive, Broadband Photodetectors, and Image Sensor Application. Adv. Sci. 2019, 6, 1901134. [CrossRef] [PubMed]

92. Yang, X.; Yan, X.; Wang, W.; Zhu, X.; Li, H.; Ma, W.; Sheng, C. Light induced metastable modification of optical properties in $\mathrm{CH}_{3} \mathrm{NH}_{3} \mathrm{PbI}_{3}-\mathrm{xBrx}$ perovskite films: Two-step mechanism. Org. Electron. 2016, 34, 79-83. [CrossRef]

93. Chen, S.; Teng, C.; Zhang, M.; Li, Y.; Xie, D.; Shi, G. A Flexible UV-Vis-NIR Photodetector based on a Perovskite/ConjugatedPolymer Composite. Adv. Mater. 2016, 28, 5969-5974. [CrossRef] [PubMed]

94. Lee, Y.; Kwon, J.; Hwang, E.; Ra, C.-H.; Yoo, W.J.; Ahn, J.-H.; Park, J.H.; Cho, J.H. High-Performance Perovskite-Graphene Hybrid Photodetector. Adv. Mater. 2015, 27, 41-46. [CrossRef] [PubMed]

95. Kang, D.-H.; Pae, S.R.; Shim, J.; Yoo, G.; Jeon, J.; Leem, J.W.; Yu, J.S.; Lee, S.; Shin, B.; Park, J.-H. An Ultrahigh-Performance Photodetector based on a Perovskite-Transition-Metal-Dichalcogenide Hybrid Structure. Adv. Mater. 2016, 28, 7799-7806. [CrossRef]

96. Wang, Z.; Yu, R.; Pan, C.; Li, Z.; Yang, J.; Yi, F.; Wang, Z.L. Light-induced pyroelectric effect as an effective approach for ultrafast ultraviolet nanosensing. Nat. Commun. 2015, 6, 8401. [CrossRef]

97. Yu, Y.; Zhang, Y.; Zhang, Z.; Zhang, H.; Song, X.; Cao, M.; Che, Y.; Dai, H.; Yang, J.; Wang, J.; et al. Broadband Phototransistor Based on $\mathrm{CH}_{3} \mathrm{NH}_{3} \mathrm{PbI}_{3}$ Perovskite and PbSe Quantum Dot Heterojunction. J. Phys. Chem. Lett. 2017, 8, 445-451. [CrossRef]

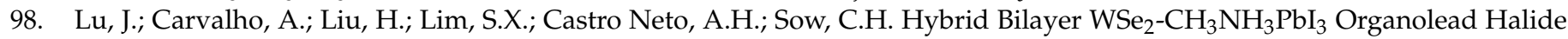
Perovskite as a High-Performance Photodetector. Angew. Chem. Int. Ed. 2016, 55, 11945-11949. [CrossRef] 
99. Long, M.; Zhang, T.; Liu, M.; Chen, Z.; Wang, C.; Xie, W.; Xie, F.; Chen, J.; Li, G.; Xu, J. Abnormal Synergetic Effect of Organic and Halide Ions on the Stability and Optoelectronic Properties of a Mixed Perovskite via In Situ Characterizations. Adv. Mater. 2018, 30, 1801562. [CrossRef]

100. Xie, C.; You, P.; Liu, Z.; Li, L.; Yan, F. Ultrasensitive broadband phototransistors based on perovskite/organic-semiconductor vertical heterojunctions. Light Sci. Appl. 2017, 6, e17023. [CrossRef]

101. Wang, Y.; Fullon, R.; Acerce, M.; Petoukhoff, C.E.; Yang, J.; Chen, C.; Du, S.; Lai, S.K.; Lau, S.P.; Voiry, D.; et al. Solution-Processed $\mathrm{MoS}_{2}$ /Organolead Trihalide Perovskite Photodetectors. Adv. Mater. 2017, 29, 1603995. [CrossRef] [PubMed]

102. Sun, Z.; Aigouy, L.; Chen, Z. Plasmonic-enhanced perovskite-graphene hybrid photodetectors. Nanoscale 2016, 8, 7377-7383. [CrossRef] [PubMed]

103. Mueller, T.; Xia, F.; Avouris, P. Graphene photodetectors for high-speed optical communications. Nat. Photon. 2010, 4, $297-301$. [CrossRef]

104. Guo, W.; Xu, S.; Wu, Z.; Wang, N.; Loy, M.M.T.; Du, S. Oxygen-Assisted Charge Transfer Between ZnO Quantum Dots and Graphene. Small 2013, 9, 3031-3036. [CrossRef]

105. Wang, H.; Kim, D.H. Perovskite-based photodetectors: Materials and devices. Chem. Soc. Rev. 2017, 46, 5204-5236. [CrossRef]

106. Ahmadi, M.; Wu, T.; Hu, B. A Review on Organic-Inorganic Halide Perovskite Photodetectors: Device Engineering and Fundamental Physics. Adv. Mater. 2017, 29, 1605242. [CrossRef]

107. Xie, C.; Nie, B.; Zeng, L.; Liang, F.-X.; Wang, M.-Z.; Luo, L.; Feng, M.; Yu, Y.; Wu, C.-Y.; Wu, Y.; et al. Core-Shell Heterojunction of Silicon Nanowire Arrays and Carbon Quantum Dots for Photovoltaic Devices and Self-Driven Photodetectors. ACS Nano 2014, 8, 4015-4022. [CrossRef]

108. Liang, F.-X.; Wang, J.-Z.; Zhang, Z.-X.; Wang, Y.-Y.; Gao, Y.; Luo, L.-B. Broadband, Ultrafast, Self-Driven Photodetector Based on Cs-Doped $\mathrm{FAPbI}_{3}$ Perovskite Thin Film. Adv. Opt. Mater. 2017, 5, 1700654. [CrossRef]

109. Hsu, C.-Y.; Lien, D.-H.; Lu, S.-Y.; Chen, C.-Y.; Kang, C.-F.; Chueh, Y.-L.; Hsu, W.-K.; He, J.-H. Supersensitive, Ultrafast, and BroadBand Light-Harvesting Scheme Employing Carbon Nanotube/ $\mathrm{TiO}_{2}$ Core-Shell Nanowire Geometry. Acs Nano 2012, 6, 6687-6692. [CrossRef]

110. Bae, J.; Kim, H.; Zhang, X.-M.; Dang, C.H.; Zhang, Y.; Choi, Y.J.; Nurmikko, A.; Wang, Z.L. Si nanowire metal-insulatorsemiconductor photodetectors as efficient light harvesters. Nanotechnology 2010, 21, 095502. [CrossRef]

111. Downs, C.; Vandervelde, T.E. Progress in infrared photodetectors since 2000. Sensors 2013, 13, 5054-5098. [CrossRef] [PubMed]

112. Zhang, B.; He, T.; Shen, J.; Hou, Y.; Hu, Y.; Zang, M.; Chen, T.; Feng, S.; Teng, F.; Qin, L. Conjugated polymer-based broadband terahertz wave modulator. Opt. Lett. 2014, 39, 6110-6113. [CrossRef] [PubMed]

113. Liu, D.; Wang, W.; Xiong, L.; Ji, H.; Zhang, B.; Shen, J. High-efficiency optical terahertz modulation of organometallic halide perovskite nanoplates on silicon. Opt. Mater. 2019, 96, 109368. [CrossRef]

114. Li, S.-H.; Li, J.-S. Terahertz modulator a using $\mathrm{CsPbBr}_{3}$ perovskite quantum dots heterostructure. Appl. Phys. B 2018, 124, 224. [CrossRef]

115. Weis, P.; Garcia-Pomar, J.L.; Höh, M.; Reinhard, B.; Brodyanski, A.; Rahm, M. Spectrally Wide-Band Terahertz Wave Modulator Based on Optically Tuned Graphene. ACS Nano 2012, 6, 9118-9124. [CrossRef] [PubMed]

116. Wang, K.-H.; Li, J.-S. Muti-band terahertz modulator based on double metamaterial/perovskite hybrid structure. Opt. Commun. 2019, 447, 1-5. [CrossRef]

117. Lyashenko, D.; Perez, A.; Zakhidov, A. High-resolution patterning of organohalide lead perovskite pixels for photodetectors using orthogonal photolithography. Phys. Status Solidi (a) 2017, 214, 1600302. [CrossRef]

118. Zhang, N.; Sun, W.; Rodrigues, S.P.; Wang, K.; Gu, Z.; Wang, S.; Cai, W.; Xiao, S.; Song, Q. Highly Reproducible Organometallic Halide Perovskite Microdevices based on Top-Down Lithography. Adv. Mater. 2017, 29, 1606205. [CrossRef]

119. Daus, A.; Roldán-Carmona, C.; Domanski, K.; Knobelspies, S.; Cantarella, G.; Vogt, C.; Grätzel, M.; Nazeeruddin, M.K.; Tröster, G. Metal-Halide Perovskites for Gate Dielectrics in Field-Effect Transistors and Photodetectors Enabled by PMMA Lift-Off Process. Adv. Mater. 2018, 30, 1707412. [CrossRef]

120. Pourdavoud, N.; Wang, S.; Mayer, A.; Hu, T.; Chen, Y.; Marianovich, A.; Kowalsky, W.; Heiderhoff, R.; Scheer, H.-C.; Riedl, T. Photonic Nanostructures Patterned by Thermal Nanoimprint Directly into Organo-Metal Halide Perovskites. Adv. Mater. 2017, 29, 1605003. [CrossRef]

121. Bar-On, O.; Brenner, P.; Lemmer, U.; Scheuer, J. Micro Lasers by Scalable Lithography of Metal-Halide Perovskites. Adv. Mater. Technologies 2018, 3, 8. [CrossRef]

122. Cegielski, P.J.; Neutzner, S.; Porschatis, C.; Lerch, H.; Bolten, J.; Suckow, S.; Kandada, A.R.S.; Chmielak, B.; Petrozza, A.; Wahlbrink, T.; et al. Integrated perovskite lasers on a silicon nitride waveguide platform by cost-effective high throughput fabrication. Opt. Express 2017, 25, 13199-13206. [CrossRef] [PubMed] 